\title{
CYSTICERCOSIS OF THE CENTRAL NERVOUS SYSTEM
}

\author{
I. SURGICAL TREATMENT OF CEREBRAL CYSTICERCOSIS
}

\author{
A 23 YEARS EXPERIENCE IN THE HOSPITAL DAS CLÍNICAS \\ OF RIBEIRÃO PRETO MEDICAL SCHOOL
}

\begin{abstract}
BENEDICTO OSCAR COLLI" , NELSON MARTELLI**, JOÃO ALBERTO ASSIRATI JR. ***, HÉLIO RUBENS MACHADO****, CÁRMINE PORCELLI SALVARANI*****,

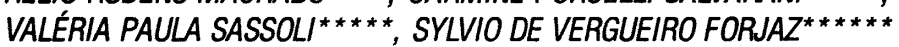

\begin{abstract}
SUMMARY - Cysticercosis is the most frequent parasitosis of the nervous system and nowadays it is widespread through the world. Despite the development of anticysticercal drugs (praziquantel and albendazole), their efficacy is more marked in cases with parenchymal active cysts and they do not prevent complications such as hydrocephalus. Thus, many patients with neurocysticercosis require surgical intervention, generally of palliative nature, but that may occasionally produce a cure. The clinical outcome of 180 patients with cerebral cysticercosis who underwent srugical treatment form 1970 to 1993 was analised. Surgical treatment was performed to control increased ICP in 177 patients and due to local compression of cranial nerves or brainstem in five. Some patients had more than one surgical procedure, totalizing 287 interventions. Increased intracranial pressure (ICP) was caused by hydrocephalus in $91 \%$, by intracranial mass lesion (tumoral form) in $6.2 \%$ and by pseudotumor cerebri (pseudotumoral form) in $2.8 \%$ of the case. Based on the pathophysiological mechanisms of intracranial hypertension identified through conventional CT-scan, ventriculography, cisternotomograpy, ventriculotomography and MRI, different surgical approaches were indicated. Patients with tumoral form were submitted to direct approach and cyst removal and generally they had benefits from this procedure. Patients with pseudotumoral form whose clinical treatment failure underwent decompressive craniectomies and had a poor outcome ( $40 \%$ of good results). Direct removal of ventricular/ cisternal cysts and/or ventriculoatrial/peritoneal shunting (VA/VPS) was performed in patients with hydrocephalus. Removal of free ventricular cysts in patients who had no ependimitis/arachnoiditis generally allowed a good outcome. Patients with adherent cysts and inflammatory process nedeed a VA/VPS posteriorly and the outcome was not so good. One hundred thirty-two patients were submitted to VA/VPS (109 as the first procedure and 23 after another surgical treatment). The VA/VPS was effective to control increased ICP, despite many complications observed mainly during the two first postoperative years. After this period the surviving patients generally had a better outcome. The patients submitted to cyst removal due to local compression of cranial nerves/brainstem generally had good results. Based on the experience acquired with the management of these patiens we present our recent policy for the treatment of patients with neurocisticercosis.
\end{abstract}

KEY WORDS: cerebral cysticercosis, hydrocephalus, intracranial pressure, surgical treatment.

Cisticercose do sistema nervoso central: I. Tratamento cirúrgico da cisticercose cerebral. Experiência de 23 anos no Hospital das Clínicas da Faculdade de Medicina de Ribeirão Preto

RESUMO - A neurocisticercose é a parasitose mais frequente do sistema nervoso e hoje em dia é encontrada em todo o mundo. Apesar do advento de drogas anticisticerco (praziquantel e albendazol), sua eficácia é comprovada apenas

Division of Neurosurgery, Department of Surgery, Ribeirão Preto Medical School (FMRP), University of São Paulo (USP): * M.D., PH.D., Associated Professor and Head of the Division of Neurosurgery; ** M.D. PH.D.., Assistant Professor; ***M.D., Assistant Physician (Neurosurgeon); ****M.D., Ph.D., Associated Professor; *****M.D. Resident; ******M.D., Ph.D., Professor of Neurosurgery. This paper will be presented ate the $\mathrm{X}$ International Congress of Neurological Surgery, Acapulco (México), October, 1993. Aceite: 26-setembro-1993.

Dr. Benedicto Oscar Colli - Department of Surgery HCFMRP Campus Universitário USP - 14048-900 Ribeirão Preto,SP - Brasil. 
nos cistos ativos parenquimatosos. Além disso, essas drogas não previnem complicações como a hidrocefalia. Portanto, número considerável de pacientes requer intervenções cirúrgicas, geralmente paliativas, mas que excepcionalmente podem ser curativas. Foram analisadas as evoluçōes clínicas de 180 pacientes com cisticercose cerebral tratados cirurgicamente no período de 1970 a 1993 . A cirurgia foi indicada para controlar a hipertensão intracraniana (HIC) em 177 pacientes e para remover compressão local de nervos cranianos ou do tronco cerebral em 5 pacientes. Vários pacientes foram submetidos a mais de um procedimento cirúrgico totalizando 287 cirurgias. A HIC intracraniana foi causada por hidrocefalia em $91 \%$ dos casos, por processo expansivo (forma tumoral) em $6,2 \%$ e por pseudotumor (forma pseudotumoral) em 2,8\%. Baseadas nos mecanismos fisiopatologicos da HIC identificados por tomografia computadorizada, ventriculografia, cisternotomografia, ventriculotomografia e/ou ressonância nuclear magnética, diferentes abordagens cirúrgicas foram indicadas. Pacientes com a forma tumoral foram submetidos a exérese dos cistos com boa evolução. Pacientes com a forma pseudotumoral que não melhoraram com tratamento clínico foram submetidos a craniectomia descompressiva e os resultados obtidos não foram bons. Exérese de cistos ventriculares ou cisternais e/ou DVADVP foram indicadas em pacientes com hidrocefalia. Os pacientes com cistos livres que não apresentavam aracnoidite/ependimite geralmente tiveram boa evolução e aqueles com cistos aderidos e/ou processo inflamatório necessitaram posteriomente de DVA/DVP e suas evoluções não foram tão boas. Cento e trinta e dois pacientes foram submetidos a DVA/DVP (109 como primeiro tratamento e 23 após outro tratamento cirúrgico). 0 controle da HIC com a DVA/DVP foi efetivo apesar do grande número de pacientes de complicações observadas durante os 2 primeiros anos pós-operatórios. Após este período, os sobreviventes geralmente tiveram boa evolução. Os pacientes submetidos à exérese de cistos que causavam compressão local apresentaram boa evolução. Baseados na experiência adquirida no manuseio desses pacientes apresentamos nossa conduta atual no tratamento dos pacientes com neurocisticercose.

PALAVRAS-CHAVE: cisticercose cerebral, hidrocefalia, hipertensão intracraniana, tratamento cirúrgico.

Neurocysticercosis is the infestation of the central nervous system (CNS) with Cysticercus cellulosae, the larval form of Taenia solium, and today represents the most frequent parasitosis of the CNS. Since this is a transmissible disease, its high incidence reflects the poor basic sanitation conditions of a population and for this reason Canelas ${ }^{24}$ considers it "a tribute paid to underdevelopment." Figure 1 is a schematic presentation of the life cycle of Taenic solium. Man usually is the definitive host of Taenia solium which lives in his intestine. The proglo tides of the parasite are eliminated with human feces and break open in the external medium, releasing a large amount of eggs. The eggs are usually ingested by pigs and their capsules are dissclved by the action of gastric juice, liberating the hexacanthous embryo. The embryo actively penetrates the intestinal mucosa and, through the lymphatic or blood circulation, eventually lodges mainly in the nervous system, muscles, subcutaneous tissue, and eyes of the animal where the embryo transforms itself into Cysticercus cellulosae. When man ingests infested pork meat, the cysticercus transforms itself into Taenia solium in his intestine, thus completing its natural evolutionary cycle. Man acquires cysticercosis when he accidentally becomes infested with Cysticercus cellulosae. Infestation may occur with parasite eggs eliminated by the individual himself (self-infestation) or by the ingestion of food (vegetable in particular) and water contaminated with parasite eggs eliminated by other persons (heteroinfestation). From an epidemiologic viewpoint, heteroinfestation represents the

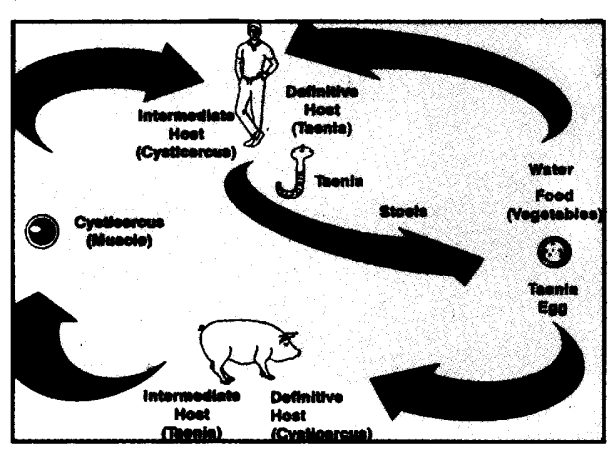

Fig 1. Life cycle of Taenia solium. most important form of acquisition of the disease. In Brazil, neurocysticercosis is important not only because of its frequency, but also because of its elevated morbidity and mortality, especially in the forms leading to increased intracranial pressure (ICP). In our hospital, neurocysticercosis has been observed in $2.7 \%$ of admitted neurological patients and $35 \%$ of these patients presented ICH alone or accompanied by other manifestations ${ }^{109}$. Despite the development of medications which can provoke degeneration of cysticerci, such as praziquantel and albendazole, experience 


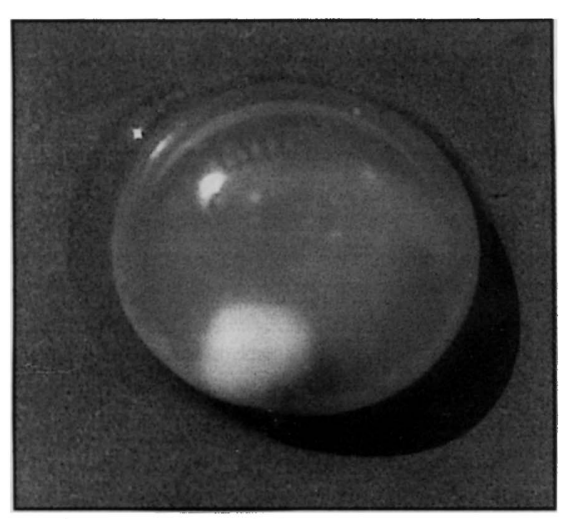

Fig 2. Cysticercus cellulosae in active fase. Note the translucent membrane, the colorless fluid and the scolex attached to the cyst wall (whistish area). accumulated over the last few years has shown that their efficacy is more marked in cases in which active cysts are present in the brain parenchyma ${ }^{1,16-}$ $94,96,97,104,108,110,119$. Their action on ventricular or cisternal cysts has been reported by some investigators ${ }^{35}$, but there still is no consensus about their efficacy in these situations. Furthermore, the use of these medications does not prevent the occurrence of complications requiring surgical treatment, such as hydrocephalus. Therefore, a considerable group of patients with neurocysticercosis need surgical procedures which are usually palliative but at times may be curative.

In the present paper we report on our experience with surgical treatment of patients with neurocysticercosis treated on the Division of Neurosurgery of the Hospital das Clínicas - Ribeirão Preto Medical School, over the last 23 years, to provide a systematic indication of the various possible surgical procedures for these cases.

Pathological Anatomy. The hexacanthous embryo reaches the CNS, specially the leptomeninges, the ventricles and the brain parenchyma, through the blood circulation, stopping at these sites by occluding a capillary. After actively crossing the capillary wall in the brain parenchyma, the embryo reaches the interstitial space where it evolves to the cystic form, transforming into Cysticercus cellulosa $e^{42}$. In this phase, the cysticercus presents a fine and translucent membrane of uniform thickness with a small denser area corresponding to the scolex of the hexacanthous embryo, and contains a colorless and transparent fluid (Fig 2). The infestation of the ventricles is attributed to active passage of hexacanthous embryo through the capillaries of the choroid plexus ${ }^{42}$, immediately followed by their transformation into cysticerci. Inside the ventricles, depending on its size, the cysticercus is carried by the cerebrospinal fluid (CSF) to the subarachnoid space. The direct arrival of hexacanthous embryo in the subarachnoid space or the ventricles through meningeal or subpial vessels is controversial ${ }^{42.74}$. After installing itself in the CNS, Cysticercus cellulosae begins to grow, usually reaching 4 to $20 \mathrm{~mm}$ in widest diameter when located inside the brain parenchyma. The cysticerci developing in the ventricles or in the subarachnoid space usually reach a larger size $e^{42,74}$ and often take on the form of Cysticercus racemosus which is characterized by a membrane of irregular thickness, by the absence of a scolex and by being usually clustered in multiple vesicles, interconnected or not, that recall a raceme (Fig 3). Although racemose cysts are frequently observed in ventricles and cisternae, they may also occur in the brain parenchyma $a^{32}$. The cysticerci present a natural evolutionary process that culminates with their degeneration within a period of 2 to 5 years ${ }^{42}$, although we have observed intraventricular cysts of more than 10 years of evolution which was in the early stage of degeneration. This degeneration process has been described by Escobar ${ }^{42}$ as a sequence of 4 stages - 1 . Vesicular Stage (live cyst or active cyst form): the cyst is characterized by a whitish, very fine and brittle translucent membrane with a 4 to 5-mm long scolex attached to it and contains a colorless, transparent fluid (Fig 2). 2. Colloidal Stage (degenerating cyst): this stage begins when the cyst starts to undergo degenerative changes due to

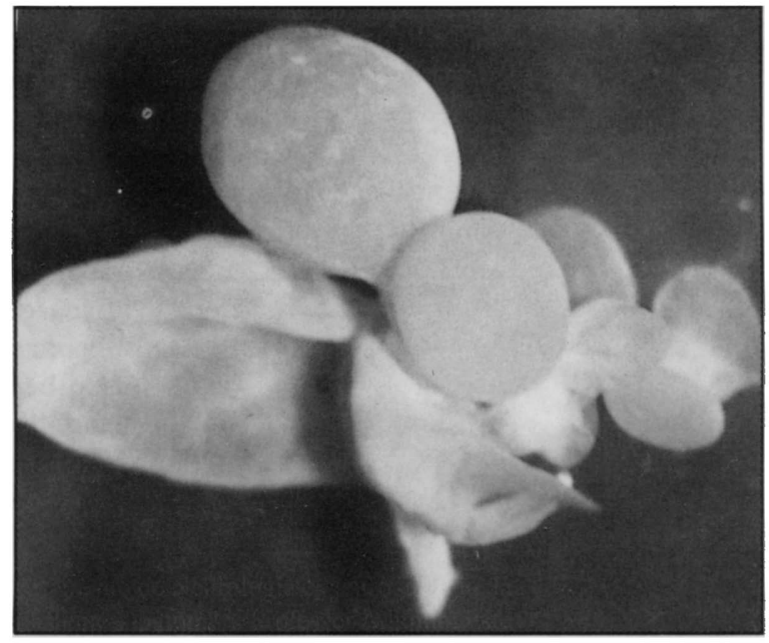

Fig 3. Cysticercus racemosus. Note the multiple vesicles without an aparent scolex with opaque membranes (degenerating cysts). 


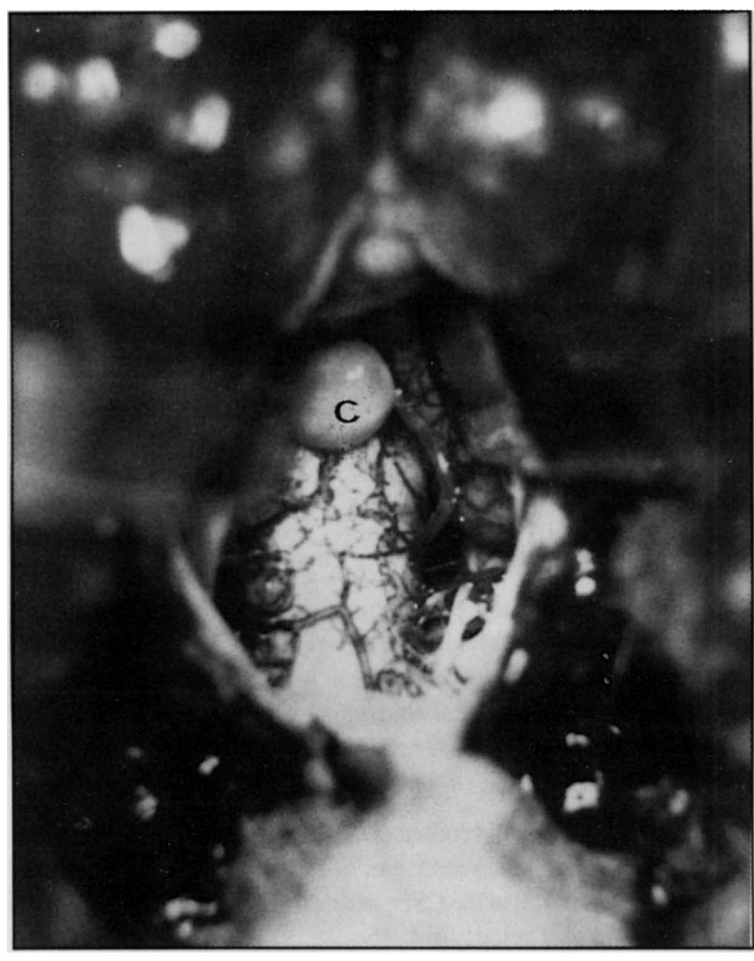

Fig 4. Surgical exposure of the posterior fossa showing the cerebellar tonsillas laterally retracted and a degenerating cysticercus (c) protruding from the forame of Magendie ("delivery" of the cysticercus). Note that the cyst membrane became opaque. normal aging or to immunological factors, characterized by thickening of the membrane and by replacement of the clear fluid with a whitish gel (Fig 4). 3. Granular Stage: the cyst starts an involution process, the wall becomes progressively thicker and the gel undergoes calcium deposition, acquiring a rough granular aspect. 4 . Calcified Nodular Stage: this is the final stage of cyst degeneration, characterized by complete calcification of the cyst, which is reduced to a third or a fourth of its original size.

The host's reaction to the cysticercus ${ }^{42,103}$ is characterized by an inflammatory process around the parasite consisting of a mononuclear lymphocyte cluster among collagen fibers, forming a capsule around the membrane of the cyst. Eosinophils and multinucleate giant cells are also observed, characterizing a granulomatous reaction to a foreign body. The inflammatory reaction to the cysticercus is related to the phase of cyst development and is less intense during the cystic or active phase, becomes more marked when the cyst starts to degenerate, and progressively declines until the cyst becomes calcified. The intensity of the inflammatory reaction depends on the parasite/host interaction in the nervous system ${ }^{42,95,103}$, which determines the production of local antibodies in response to nervous tissue macromolecules. These macromolecules become immunocompetent or associate with heteroantigens, possibly leading to self-lesion. When the cyst is in direct contact with cerebrospinal fluid (CSF) in the ventricles or in the subarachnoid space, the inflammatory reaction triggered by it may extend to other sites and provoke extensive areas of inflammation in the cisterns and meninges, generally associated with the presence of cysts. In parallel, the clinical manifestations become acute and the CSF presents increased numbers of cells and higher protein content, as well as positivity to immunodiagnostic reactions, demonstrating continued activity of the immunological reaction to the cysticercus.

Due to the different individual responses to the cysticercus, infestation of the parenchyma by large numbers of cysts may be observed without evidence of a significant inflammatory reaction and with unchanged CSF tests. Conversely, infestation by a small number of cysts is occasionally accompanied by an intense inflammatory reaction appearing as extensive parenchymal edema in the computerized tomography scan(CT). When exacerbated, the inflammatory reaction to the cysticerci may characterize a pseudotumoral picture ${ }^{105,106}$ more frequently observed in children than in adults $18,20,42,51,97,105,106$.

Clinical Manifestations. The clinical manifestations of neurocysticercosis result from the different locations of the cysticerci in the CNS and from the parasite/host interaction, with the consequent possible occurrence of an extensive variety of signs and symptoms reflecting the involvement of several regions of the CNS. Generically, one can observe signs and symptoms resulting from involvement of the brain parenchyma (convulsive seizures and localizing signs), signs of meningeal involvement, signs of intracranial hypertension, and signs of involvement of the spinal cord and roots.

Cysticercosis of the CNS is characterized by recurrent clinical manifestations resulting from exacerbation of the inflammatory reaction in the brain parenchyma and in the CSF caused by cyst degeneration. These exacerbations are caused by the immunological reaction to heteroantigens that form after successive degenerations of cysticerci and that may cause severe lesions of the CNS due to their chronic repetitive nature ${ }^{103}$. The cysticerci from the same infestation undergo a process of natural degeneration of different duration for each cyst ( 2 to 5 years ${ }^{42}$ till more than 
10 years - personal observation). This makes cysticercosis a self-limiting disease if there is no reinfestation but, despite the end of the disease, severe sequelae such as hydrocephalus and focal neurological signs caused by the involvement of the brain parenchyma may persist.

Several classifications of cysticercosis do the CNS have been elaborated on the basis of topography ${ }^{10,11,19,48,49,56,75,77}$, pathophysiology ${ }^{105,106}$, and clinical forms ${ }^{9,24,43,79,99,100,109,114,115}$. More recently, other classifications for the different forms of manifestation of neurocysticercosis have been proposed, mainly based on the evolutionary phase of the cysticerci detected by CT or magnetic resonance image (MRI) or on the sequelae observed during these examinations ${ }^{15,95}$, as opposed to the earlier classifications based on cyst location and on clinical manifestations. From a neurosurgical viewpoint, these classifications are of little practical importance since the indication for a surgical procedure in patients with neurocysticercosis is mainly based on the presence of clinical manifestations which pose a risk to life or which are caused by local compression. Much more important for the indication of the most appropriate surgical procedure is the perfect identification of the pathophysiological mechanism causing these clinical manifestations.

\section{CLINICAL MATERIAL AND METHODS}

A total of 180 patients with neurocysticercosis requiring surgical treatment was seen at the Division of Neurosurgery of the Hospital das Clínicas - Ribeirão Preto Medical School - University of São Paulo, from 1970 to June 1993. The patients were submitted to surgical treatment to control of increased ICP, for the removal of cysts causing local compression and, exceptionally, for diagnosis. The clinical course of these patients was analyzed retrospectively (before 1980:48 patients) and prospectively (after 1980: 132 patients). Part of them was included in a previous study ${ }^{33}$.

Besides clinical and epidemiological findings, the diagnosis of cerebral cysticercosis was made by antigenantibody reactions (complement fixation reaction, indirect immunofluorescence test, ELISA) in the CSF of 60 patients, from cellular changes (pleocytosis with more than $2 \%$ eosinophils ${ }^{102}$ ) in the CSF plus with neuroradiological findings in 16 , from neuroradiological findings in 86 , at surgery in 4 , and at autopsy in 4 . The neuroradiological examinations used were skull $X$-rays, carotid angiography, pneumoencephalography, pneumoventriculography, ventriculography with positive contrast medium, CT and MRI of the brain. The first 4 examinations were used in the first patients of this series, but today their use has been abandoned. The criteria used for the diagnosis of cysticercosis in the neuroradiological examinations were the presence of two or more calcifications in the X-ray or in CT, two or more cysts in CT, images suggesting cysts in ventriculography, and inflammatory obstruction of the aqueduct or fourth ventricle in ventriculography in patients coming from an area endemic for the disease.

In the evaluation of the results, the patients submitted to surgical treatment to control increased ICP were classified as: improved when there was full remission of clinical signs of lincreased ICP; unchanged when signs of hypertension persisted despite surgery; and worsened when the surgical procedure or its complications resulted in worsening of the clinical picture or in patient death. Several patients considered improved at final evaluation required one or more revisions of the shunt and others continued to have neurological sequelae caused by the disease, usually some visual deficit.

The results of treatment of patients submitted to cyst exeresis in the optochiasmatic region were evaluated by comparison of subjective and/or objective exams for the evaluation of vision during the pre- and postoperative periods and were classified as improved, unchanged or worsened. The patients submitted to exeresis of intraventricular or parenchymatous giant cysts were evaluated for signs of intracranial hypertension and also for the course of the clinical signs resulting from local compression and from the mass effect of the lesion.

The quality of survival was considered: good when the patient was able to return to work; moderate when he was able to become self-sufficient for his daily activities; and poor when he was confined to his bed. Operative mortality was considered: early when death occurred during the first 30 days after surgery; and late when death occurred after the 30 th postoperative day.

\section{SUMMARY OF CASES}

\section{Clinical Features and Examinations}

Patient age at the onset of the disease ranged from 5 to 67 years; $144(80 \%)$ were 10 to 50 years old and 83 (46.1\%) were 20 to 40 years old (mean, 34.1 years). Ninety-two (51.1\%) patients were females and 88 (48.9\%) were males. 

180 patients.

Cases

Signs and Symptoms

\begin{tabular}{lcc} 
& Number & Percent \\
\hline \hline papilledema/or optic atrophy & 105 & $58,3 \%$ \\
headache & 93 & $51,7 \%$ \\
gait apraxia & 39 & $21,7 \%$ \\
nauseas and vomiting & 39 & $21,7 \%$ \\
neck stiffness & 23 & $12,8 \%$ \\
vertigo & 20 & $11,1 \%$ \\
pyramidal signs & 18 & $10,0 \%$ \\
somnolence & 16 & $8,9 \%$ \\
confusion & 10 & $5,5 \%$ \\
seizures & 9 & $5,0 \%$ \\
aphasia & 8 & $4,4 \%$ \\
altered mental status & 8 & $4,4 \%$ \\
Impairment of cranial nerves & 8 & $4,4 \%$ \\
VI & 1 & $0,5 \%$ \\
VII & 5 & $2,8 \%$ \\
VIII & 3 & $1,7 \%$ \\
coma & 7 & $3,9 \%$ \\
nystagmus & 7 & $3,9 \%$ \\
altered sensation & 4 & $2,2 \%$ \\
sphincter disturbance & 3 & $1,7 \%$ \\
dysmetria & 3 & $1,7 \%$ \\
truncal ataxia & 2 & $1,1 \%$ \\
Parinaud's syndrome & 1 & $0,5 \%$ \\
& & \\
\hline
\end{tabular}

Table 1. Clinical signs and symptoms at admission in

The duration of symptoms upon admission ranged from one day to 33 years $(68.7 \%$ of patients had symptoms for less than one year, $60.3 \%$ for less than 6 months, $33.5 \%$ for less than one month, and $6.1 \%$ for less than one day). The most frequent signs and symptoms upon admission are presented in Table 1. Signs of increased ICP were present in 178 (98.9\%) patients and intracranial hypertension was caused by hydrocephalus in $157(88.9 \%)$ patients, by cerebral edema (cystercotic encephalitis or pseudotumoral form) in $5(2.8 \%)$ patients, by giant cysts behaving as expansive lesions (tumoral form) in $8(4.5 \%)$, and by combined giant cysts and hydrocephalus in $4(2.2 \%)$, for a total of $161(90.5 \%)$ patients with hydrocephalus and $12(6.7 \%)$ with the tumoral form. Seven patients presented also signs of spinal cord, radicular or cauda equina compression associated with the signs of intracranial involvement.

One or more CSF samples were studied during different periods of the disease in $138(76.7 \%)$ patients. Moderate pleocytosis was observed in $48.9 \%$ of cases and marked pleocytosis was observed in $12.8 \%$, for a total of $61.7 \%$ of cases; eosinophilia of more than $2 \%$ was observed in $28.7 \%$ of cases, increased protein rate in $31.1 \%$ of cases; reduced glucose rate in $20.2 \%$, reduced chloride rates in $5.4 \%$, and a positive antigenantibody reaction for cysticercosis in $42.9 \%$ of cases.

A skull X-ray was taken in 94 (52.2\%) patients. Calcifications suggesting cysticerci were observed in $15(15.9 \%)$ patients, and signs of increased ICP in 30 (31.9\%) (erosion of the sella turcica in $28.7 \%$, suture diastasis in $3.2 \%$, and increased convolutional markings in $8.5 \%$ ). In addition, erosions of the skull base not involving the sella turcica were observed in 3 patients.

Carotid angiography was performed in $56(31.1 \%)$ patients and showed hydrocephalus in $44(78.6 \%)$ and expansive processes in $6(10.7 \%)$. Contrasted examinations of the encephalic cavities were performed on 101 (56.1\%) patients (pneumoencephalography in 4, pneumoventriculography in 30 and ventriculography with positive contrast in 67 patients). The results of these examinations are presented in Table 2.

Computerized tomography of the skull was performed on 111 (61.7\%) patients. Hypodense nodules (active cysts) were observed in the brain parenchyma of $27(24.3 \%)$ patients, intensely contrasted nodules or nodules with annular contrast uptake (degenerating cysts) were observed in 4 (3.6\%), and calcification in 37 (33.3\%). Giant cysts were observed in $10(9.0 \%)$ patients. In addition to cysts or parasite remnants, diffuse brain edema was observed in 2 (1.8\%) patients and perilesional edema in $7(6.3 \%)$. With respect to the ventricular system, dilatation of the lateral ventricles was observed in $8(8.1 \%)$ patients, dilatation of the third ventricle and of the lateral ventricles in $52(46.8 \%)$, and global dilatation in $34(30.6 \%)$, for a total of $95(85.6 \%)$ patients with hydrocephalus. Deformations of the lateral ventricles and of the third or of the fourth ventricle were observed in several patients. These were usually rounded deformations suggesting the presence of cysts inside them, a fact that was not always confirmed by ventriculography. However, contrast enhancement along the wall of the fourth ventricle was observed in only 3 patients, suggesting the presence of degenerating cysts adhering to the ventricular wall, as confirmed at surgery. CT was performed with intraventricular positive contrast (ventriculotomography) in 11 patients, revealing hydrocephalus in all of them and the presence of single or multiple intraventricular cysts in $10(90.9 \%)$. Tomography with positive intrathecal contrast (cisternotomography) was performed in 17 patients, revealing cysts in the basal cisternae in $5(29.4 \%)$. In several patients, the contrast penetrated the ventricular system, delineating intraventricular cysts in 6 of them.

Three patients were submitted to MRI of the brain and a rounded dilatation of the fourth ventricle was observed in all of them, suggesting the presence of a cyst inside the ventricle, although cysts were not demonstrated directly by this examination. 
Table 2. Ventriculographic findings in 101 patients.

\begin{tabular}{|c|c|c|c|c|c|c|c|c|c|c|}
\hline \multirow{3}{*}{$\begin{array}{c}\text { Type } \\
\text { of } \\
\text { Examination }\end{array}$} & \multirow{3}{*}{$\begin{array}{c}\mathbf{N}^{\circ} \\
\text { of } \\
\text { Cases }\end{array}$} & \multirow{3}{*}{$\begin{array}{l}\text { Normal } \\
\text { Studies }\end{array}$} & \multirow{3}{*}{$\begin{array}{l}\text { Non- } \\
\text { obstru- } \\
\text { ctive } \\
\text { Hydro- } \\
\text { cepha- } \\
\text { lus }\end{array}$} & \multicolumn{6}{|c|}{ Obstructive Hydrocephalus } & \multirow{3}{*}{$\begin{array}{l}\text { Cysts in } \\
\text { More } \\
\text { Than } \\
\text { One } \\
\text { Ventri- } \\
\text { cle }\end{array}$} \\
\hline & & & & \multicolumn{2}{|c|}{$\begin{array}{c}4 \text { th } \\
\text { Ventricule }\end{array}$} & \multicolumn{2}{|c|}{ Aqueduct } & \multicolumn{2}{|c|}{$\begin{array}{c}3 \text { rd } \\
\text { Ventricule }\end{array}$} & \\
\hline & & & & Inflam & Cysts & Inflam & Cysts & Inflam & Cysts & \\
\hline pneumoencephalography & 4 & 2 & 2 & 0 & 0 & 0 & 0 & 0 & 0 & 0 \\
\hline $\begin{array}{c}\text { central } \\
\text { pneumoventriculography }\end{array}$ & 30 & 1 & 14 & 9 & 1 & 6 & 0 & 0 & 0 & 0 \\
\hline $\begin{array}{l}\text { ventriculography with } \\
\text { positive contrast medium }\end{array}$ & 67 & 3 & 11 & 10 & 25 & 6 & 3 & 6 & 1 & 6 \\
\hline total cases & 101 & 6 & 27 & 19 & 26 & 12 & 3 & 6 & 1 & 6 \\
\hline
\end{tabular}

\section{Surgical Treatment and Results}

The 180 patients studied were submitted to a total of 287 surgical procedures including 61 ventricular reservoir (RES) implantations, 144 ventriculoatrial (VAS) or ventriculoperitoneal (VPS) shunts, 14 hypothalamic catheter ventriculostomies and 3 Torkildsen ventriculostomies, 37 craniotomies of the posterior fossa (CPF) for cyst exeresis in the third ventricle or in the cisternae, 8 craniotomies for cyst exeresis in the third ventricle and/or lateral ventricles (7 transcallosal approaches and one approach to the temporal horn through the base of the temporal lobe), five bilateral decompressive craniotomies, 12 supratentorial craniotomies for exeresis of giant parenchymatous or cisternal cysts, and 3 pterional craniotomies for cyst exeresis in the optochiasmatic region.

Of the 3 patients submitted to pterional craniotomy for cyst exeresis in the optochiasmatic region, 2 were improved and one was unchanged during a postoperative follow-up of 2 to 4 years.

CPF with or without cyst exeresis was performed in 37 patients (as first surgery in 8, after RES implantation in 18 , and after VAS/VPS in 11). Of the 26 patients initially submitted to CPF or RES implantation followed by CPF, 10 presented free cysts in the 4 th ventricle and one presented a free cyst in the cerebellopontine cistern without an associated inflammatory reaction or with discrete arachnoiditis and/or ependymitis. Nine of these patients (90\%) presented improvement of the increasead ICP signs. Fifteen patients presented degenerating cysts in the fourth ventricle and/or cysts in the cisterna magna and in the cerebellopontine and perimesencephalic cisterns, associated with an inflammatory reaction (ependymitis and/or arachnoiditis). The patients who presented only an inflammatory reaction (ependymitis and/or arachnoiditis) of the posterior fossa or an inflammatory reaction and degenerating cysts in the fourth ventricle and/or cysts in the cisterna magna, and in the cerebellopontine and perimesencephalic cisterns, operated up to 1987 (8 patients) presented a transitory improvement of increased ICP and required a VAS/VPS within a period of one month (5 patients) to 4 years. Starting in 1987, all patients with these surgical findings at CFP were immediately submitted to VPS. Five (13.5\%) of the 37 patients submitted to CPF, all with inflammatory obstruction of the fourth ventricle or degenerating cysts associated with an inflammatory reaction (arachnoiditis and/ or ependymitis) of the posterior fossa, suffered transitory or permanent neurologic worsening. The global mortality of patients submitted to CPF was $24.3 \%$ (9 patients). Of these, $5(13.5 \%$ ) died as a consequence of surgery ( 2 early and 3 late deaths). All of these 5 patients presented an inflammatory reaction in the posterior fossa (arachnoiditis and/or ependymitis).

Of the 9 patients submitted to a direct approach of the lateral and/or third ventricles for cyst exeresis, 4 $(44,4 \%)$ received this as the first treatment; three of them presented free intraventricular cysts and one presented degenerated cysts and associated ependymitis. All patients with free cysts experienced improvement of the increased ICP signs and the patient with degenerated cysts and associated ependymitis was immediately submitted to VPS. Five patients previously submitted to VPS also had a direct approach of the lateral and/or third ventricles because the cysts behaved like expansive intraventricular processes. During surgery, free cysts were found in one patient and degenerated cysts with associated ependymitis were found in 4 . Four of these patients presented improved symptoms of local compression and one died of bacterial meningitis a few days after the direct approach. 
Table 3. Evolution of increased intracranial pressure signs after ventriculoatrial/ventriculo peritoneal shunting.

\begin{tabular}{|c|c|c|c|c|c|c|c|c|c|}
\hline \multirow{3}{*}{ ICP Status } & \multicolumn{9}{|c|}{ Postoperative Follow-up } \\
\hline & \multicolumn{9}{|c|}{ Months } \\
\hline & $0-3>$ & $3-6>$ & $6-9>$ & $9-12>$ & $12-15>$ & $15-18>$ & $18-21>$ & $21-24>$ & \\
\hline Improved & 136 & 125 & 114 & 100 & 91 & 85 & 81 & 79 & \\
\hline Unchanged & 0 & 0 & 1 & 1 & 0 & 1 & 0 & 0 & \\
\hline Worsened & 6 & 0 & 0 & 0 & 0 & 0 & 0 & 0 & \\
\hline Death & 2 & 6 & 0 & 2 & 5 & 2 & 1 & 1 & \\
\hline Follow-up Ended & 0 & 5 & 8 & 1 & 4 & 3 & 3 & 1 & \\
\hline \multirow{2}{*}{ ICP Status } & \multicolumn{9}{|c|}{ Years } \\
\hline & $>2-3$ & $>3-4$ & $>4-5$ & $>5-6$ & $>6-7$ & $>7-8$ & $>8-9$ & $>9-10$ & $>10$ \\
\hline Improved & 77 & 67 & 61 & 59 & 50 & 43 & 37 & 28 & 15 \\
\hline Unchanged & 2 & 1 & 0 & 0 & 0 & 0 & 1 & 0 & 5 \\
\hline Worsened & 0 & 0 & 0 & 0 & 0 & 0 & 0 & 0 & 0 \\
\hline Death & 0 & 0 & 0 & 1 & 2 & 0 & 1 & 0 & 2 \\
\hline Follow-up Ended & 0 & 9 & 6 & 1 & 7 & 7 & 4 & 9 & 6 \\
\hline
\end{tabular}

Bilateral temporal decompressive craniotomy was performed in 5 patients with ICP caused by the pseudotumoral form who had not responded to clinical treatment. Three of them $(60 \%)$ presented improvement of the signs of intracranial hypertension and two (40\%) did not improve and died a few days after surgery. Despite remission of the increased ICP, one patient died as a consequence of the course of his disease.

The 12 patients submitted to exeresis of giant parenchymatous or cisternal cysts presented early improvement of intracranial hypertension and regression of focal signs due to compression of the nervous tissue. One patient with cisternal cysts had been previously submitted to VPS and 3 other patients suffered recurrent increased ICP, requiring later VPS. All patients are doing well after a follow-up time of one year and 6 months to 17 years.

Six patients were submitted only to RES implantation and 4 presented definitive improvement of intracranial hypertension signs, remaining asymptomatic for nine to 13 years. The other 2 patients died early after reservoir implantation, one of them of bacterial meningitis and the others of intracranial hypertension, before other surgical procedures could be performed. The 3 patients treated with a Torkildsen ventriculostomy and 9 patients (64.3\%) treated with a hypothalamic catheter ventriculostomy presented early recurrence of increased ICP signs due to catheter obstruction and required a VAS/VPS. The remaining 5 patients with a hypothalamic catheter ventriculostomy continue to be asymptomatic after a period of 11 to 18 years.

A total of 124 patients was submitted to VAS/VPS as first surgery and 20 were submitted to the procedure after previous ones that failed to control increased ICP. The shunt systems used were: Phoenix in 95 patients, Hakim in 23, Pudenz in 12, Cordis in 9, Orbis-Sigma in 8, Ames in 7, Dow Corning in 7, and unidentified in 12. The evolution of clinical signs of intracranial hypertension in the patients submitted to VSP/VPS is presented in Table 3. Considering the patients who were followed for 2 or more years, most of them were free from intracranial hypertension at the end of 2 years, although some of them were submitted to one or more revisions of the shunt.

The quality of survival of in this serie of patients is presented in Table 4.

Ninety-seven (67.4\%) of the 144 patients submitted to VAS/VPS required one or more readmissions to the hospital. The neurologic causes of readmission were meningitis on 52 occasions (cysticercotic in 33, bacterial in 14 and cysticercotic/bacterial in 5), cerebrospinal fistula in 5, and convulsive seizures in 4. Causes of readmission other than neurological were: malfunctioning shunt in 49 , general problems in 36 , diagnostic procedures in 6 , and other causes in 22. 
Table 4.Quality of survival of all patients.

\begin{tabular}{|c|c|c|c|c|c|c|c|c|c|}
\hline \multirow{3}{*}{$\begin{array}{l}\text { Quality of } \\
\text { Survival }\end{array}$} & \multicolumn{9}{|c|}{ Postoperative Follow-up } \\
\hline & \multicolumn{9}{|c|}{ Months } \\
\hline & $0-3>$ & $3-6>$ & $6-9>$ & $9-12>$ & $12-15>$ & $15-18>$ & $18-21>$ & $21-24>$ & \\
\hline Good & 163 & 148 & 138 & 132 & 123 & 117 & 111 & 108 & \\
\hline Moderate & 4 & 1 & 1 & 2 & 0 & 1 & 0 & 0 & \\
\hline Poor & 1 & 1 & 0 & 0 & 0 & 0 & 0 & 0 & \\
\hline Death & 12 & 6 & 1 & 2 & 5 & 2 & 1 & 1 & \\
\hline Follow-up Ended & 0 & 9 & 8 & 2 & 4 & 3 & 5 & 2 & \\
\hline \multirow{2}{*}{$\begin{array}{c}\text { Quality of } \\
\text { Survival }\end{array}$} & \multicolumn{9}{|c|}{ Years } \\
\hline & $>2-3$ & $>3-4$ & $>4-5$ & $>5-6$ & $>6-7$ & $>7-8$ & $>8-9$ & $>9-10$ & $>10$ \\
\hline Good & 107 & 94 & 88 & 87 & 76 & 64 & 57 & 46 & 32 \\
\hline Moderate & 1 & 3 & 0 & 0 & 0 & 0 & 1 & 0 & 4 \\
\hline Poor & 0 & 0 & 1 & 0 & 0 & 0 & 0 & 0 & 0 \\
\hline Death & 0 & 0 & 1 & 1 & 3 & 0 & 1 & 0 & 2 \\
\hline Follow-up Ended & 0 & 10 & 4 & 0 & 10 & 12 & 5 & 11 & 6 \\
\hline
\end{tabular}

Seventy-eight (54.2\%) of the 144 patients submitted to VAS/VPS, 9 (64.3\%) of the 14 submitted to a hypothalamic catheter ventriculostomy, and all 3 patients submitted to a Torkildsen ventriculostomy were reoperated upon one or more times, for a total of 19 procedures in 161 patients ( 0.8 procedures per patient). Eighty-two of the reoperative procedures were performed during the first postoperative year, and 97 (78.2\%) during the first and second postoperative years. The main cause of reoperation in patients with VAS/VPS was malfunctioning of the shunt which occurred in 95 (73.6\%) of the patients (malfunctioning without obstruction on 32 occasions, occlusion or poor positioning of the ventricular catheter in 31 , occlusion of the distal catheter in 26 , cerebrospinal fistula in 4 , a ruptured catheter in one, and an extruded catheter in another). Other causes of reoperation of these patients were infections of the system on 16 occasions and miscellaneous on 17 occasions.

Postoperative bacterial infections occurred in $9 \%$ of the surgical procedures performed. Of these, $20(57.1 \%)$ were meningitis and $15(42.9 \%)$ other infections (pulmonary, urinary, sepsis, and abdominal). Among the 273 procedures for VAS/VPS implantation and revision, $13(4.8 \%)$ presented one or more episodes of meningitis. In most cases $(85 \%)$ the microorganisms causing the meningeal infection were not identified.

Early, late and global mortality rates were $3.4 \%, 4.8 \%$ and $21.5 \%$, respectively, in patients with VAS/VPS, and $8.1 \%, 13.5 \%$ and $24.3 \%$ in patients submitted to CPF. Among patients submitted to supratentorial decompressive craniotomy, early mortality was $20 \%$ and late mortality $40 \%$. Among patients submitted to reservoir implantation, early mortality was $3.3 \%$. One patient $(11.1 \%$ ) underwent direct approach of the lateral ventricle for cyst exeresis died early. There were no deaths among the patients submitted to a hypothalamic catheter ventriculostomy, to a Torklidsen ventriculostomy or to supratentorial craniotomy for cyst exeresis.

\section{COMMENTS}

Today the diagnosis of brain cysticercosis is based not only on clinical and epidemiological manifestations but also on immunodiagnostic reactions in the CSF, on neuroradiological examinations, specially CT and MRI, and, eventually, on surgical observation.

The changes observed in the CT of patients with cerebral cysticercosis have been described by several authors ${ }^{13,21,31,33,52,60,63,71,87,89,107,121}$ and they are related to the cysticercus phase and to disease evolution. They include edema of the brain parenchyma, hypodense nodular areas of 1 to $3 \mathrm{~cm}$ in the parenchyma or the cisterns with no contrast enhacement (active cysts) or with annular contrast enhancement (degenerating cysts), amorphous masses with high contrast enhancement in the 


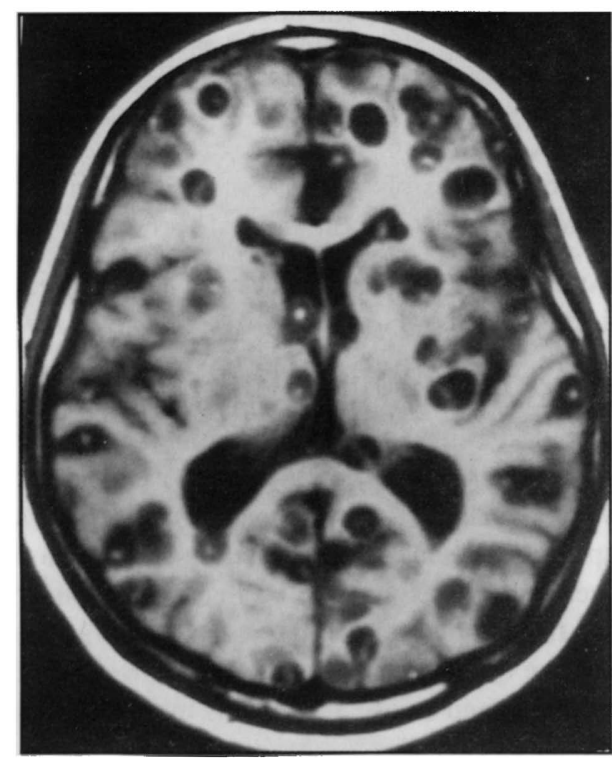

Fig 5. Magnetic resonance image of brain: axial section (SE 520/20). Multiple actice cysticercus (low signal intensity lesions) and degenerating cysts (lesions with increased signal intensity in relation to active cysts). Note the scolex in several cysts (increased signal intensity area in the cyst). parenchyma and cisterns (degenerating cysts), parenchymatous calcifications of various aspects (single or multiple), ventricular dilatation, and, occasionally, cysts with annular contrast enhancement in the ventricles.

The main features observed in MRI of patients with cerebral cysticercosis have been related by several authors ${ }^{57,69,111}$. Cysts present in the brain parenchyma, in their active form, appear as lesions with a sign intensity similar to that of the CSF in T1. When they have a scolex, this appears to have a hyperintense sign in $\mathrm{T} 1$ (Fig 5). When the cyst starts to degenerate, the inflammatory reaction occurring around it has the aspect of a hyperintense halo in T1. The active cysts located in the ventricles are usually isointenses with the CSF and are visualized by indirect signs such as the mass effect, the void of the adjacent CSF flow, and obstruction of the ventricular flow (Fig 6). Degenerating ventricular cysts show an increased signal in T1 (Fig 7) and the pericystic ependymal inflammatory reaction has the appearance of a hiperintense ring in T2. The cisternal cysts behave like the intraventricular ones. MRI reveals calcifications
and $T 2$. In addition to these findings, MRI shows appearing as areas of low signal intensity in $\mathrm{T} 1$ and T2. In addition to these findings, MRI shows
ventricle dilatation and obstruction or impairement of the CSF flow through the ventricular cavities. Although highly useful, because of its high cost MRI is an examination to which most of our patients have no access.

The experience in the treatment of cerebral cysticercosis in our hospital can be divided into the period preceding 1980 and the period starting that year. During the first period the difficulties in identifying the different forms and the locations of the lesions were greater since in most cases only angiography and ventriculography were available to us. Consequently we had no defined conduct for the treatment of these patients and the results of direct approaches (to the posterior fossa and supratentorial, specially ventricular approaches), did not always yield good results. However, this period was important because that was when most of the patients were submitted to VAS/VPS, thus permitting us to evaluate this treatment on a long-term basis and in a large number of cases. Since 1980, when it became possible for us to use CT, cisternotomography, ventriculotomography and, more recently, MRI, we have been trying to identify the pathophysiological mechanisms of the lesions, specially those causing intracranial hypertension, and to plan the best therapeutic approach according to this information. Besides the better diagnostic conditions, the systematic execution of interventions using microsurgical techniques has contributed to improvement of the results for select cases.

Among the clinical forms of cysticercosis of the CNS that can be treated surgically are the spinal form which evolves with signs of compression of the spinal cord or of roots and cauda equina, the forms which evolve with signs of local compression of the brain and of cranial nerves, and the forms that evolve with intracranial hypertension. The epileptic form is the most frequent and its victims often present epileptic seizures that cannot be well controlled with medicines. Although very little has been done in this field ${ }^{27,120}$, some patients may benefit from surgical treatment of epilensv. 

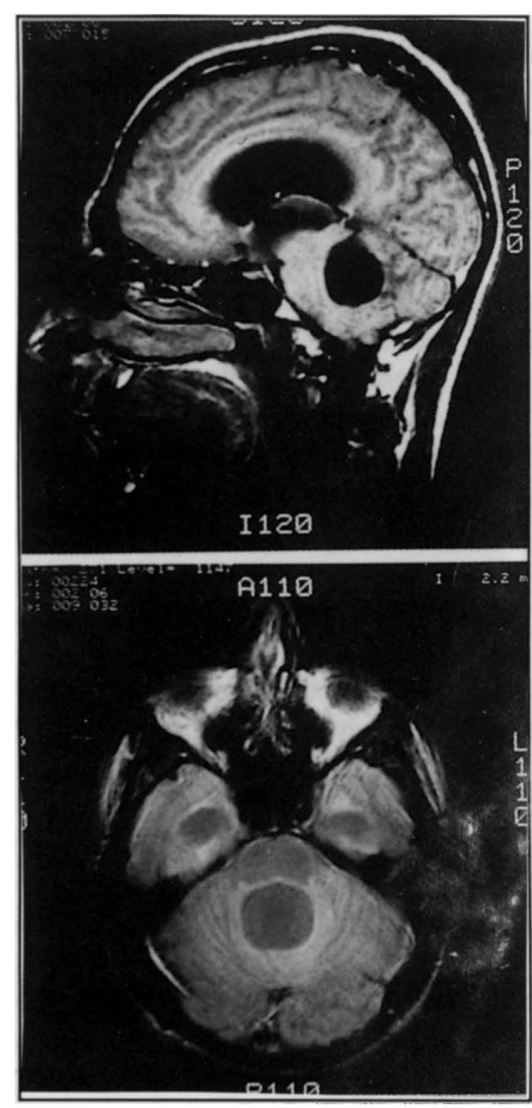

Fig 6. Magnetic resonance image of the brain: sagittal (upper, SE 500/20) and axial (botton, SE 2500/0) sections. The fourth ventricle is enlarged and rounded, suggesting a cyst in the ventricle confirmed during surgical exploration. It was an active cyst not direct showed by magnetic resonance $i$-naging.

\section{Cisternal Forms that Causes Local Compression}

This group involves patients presenting cysticerci, usually racemose and of varying size, in the basal cisterns, with symptoms of local compression independent of possible clinical manifestations of intracranial hypertension resulting from hydrocephalus.

Among the cranial nerve that can be most affected by local compression by the cysticerci or by arachnoiditis are the optic nerve and the chiasma, the oculomotor nerve, the trigeminus, and the facial nerve ${ }^{12}$. The cysts located in the cerebellopontine angle may cause a characteristic syndrome evolving several nerves or only trigeminalgia ${ }^{24}$. Other clinical manifestations of compression include signs caused by compression of the cerebral cortex and the Parinaud syndrome ${ }^{24}$ resulting from compression by cysts located in the cistern of the quadrigeminal lamina. Compression of the optic nerve and chiasma (Fig 8) is more frequent and may be caused directly by cysticerci or by an inflammatory reaction (optochiasmatic arachnoiditis) and is clinically manifested as progressive disorders of the visual field ${ }^{12}$.

Direct surgical removal of the cysticerci in the basal cisterns is not an effective procedure since only exceptionally are all cysts removed because they are usually multiple and are frequently partially degenerated and adhering to the cranial nerves, to the vessels and to the brain parenchyma owing to arachnoiditis. An attempt at full lysis of arachnoiditis in this situation may have disastrous consequences.

However, surgical removal of free cysts and even of degenerating cysts causing well defined localized compressions may be beneficial, as observed in some of our cases and by other authors ${ }^{12}$. Examples of this situation are the stabilization or improvement of visual disorders and of the Parinaud syndrome observed after exeresis of cysts in the optochiasmatic (Fig 9) and in the quadrigeminal lamina cisterns, respectively, or of signs of brainstem compression by cysts in the cerebellopontine angle (Fig 10). However, removal of the cysts does not prevent the progression of the inflammatory reaction already undcrway, leading to results that are often only transitory.

\section{Forms Progressing to Intracranial Hypertension}

The forms of n: iocysticercosis in which patients develop intracranial hypertension are quite frequent, with incidence ranging from 25 to $65.9 \%{ }^{24,52,66,71,82,90}$. In our hospital they were observed alone or in combination with other clinical forms in $35.7 \%$ of the patients ${ }^{109}$.

In 1949, Stepièn and Choróbski ${ }^{106}$ classified the hypertensive forms of neurocysticercosis into 3 groups according to their pathophysiological mechanism: I. hypertension due to the presence of cysticerci that occupy space inside the skull (tumoral form); II. hypertension caused by diffuse cerebral edema (pseudotumoral form), and III. hypertension due to hydrocephalus caused by obstruction of CSF circulation by cysticerci or by an inflammatory reaction. At our hospital, of the 


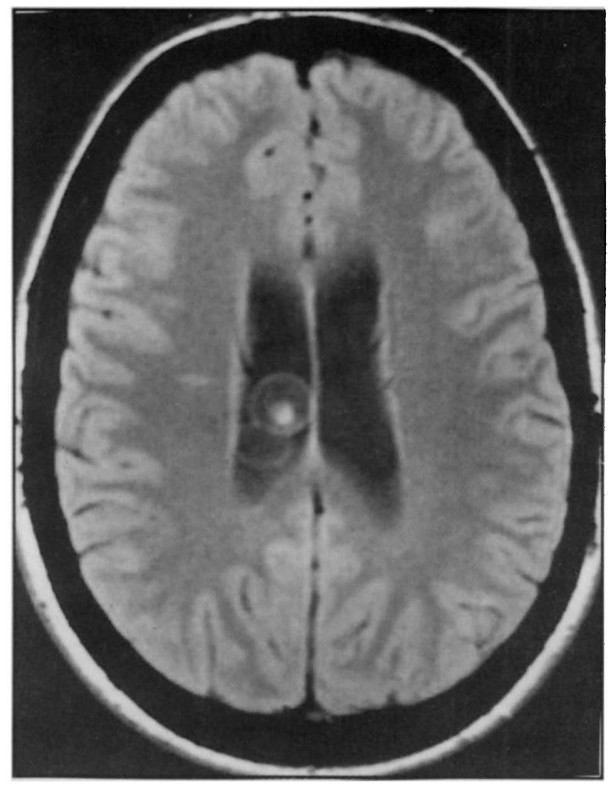

Fig 7. Magnetic resonance image of the brain: axial section (SE 520/20) showing two cysticercus in the left lateral ventricle. The increased signal intensity of the membranes indicate that the cysts are degenerating. The scolex is evident as a high signal intensity area in one of the cysts.

coefficient of attenuation similar to that of CSF, are uni- or multiloculated, and with little or no contrast enhancement around them (Fig 11). The occurrence of multiloculated cysts or the association of smaller cysts or multiple calcifications in other regions of the brain of patients originating from endemic regions gives more specificity to the tomographic diagnosis of cerebral cysticercosis ${ }^{8,17,31,45,83,87}$. Out of these situations the differential diagnosis with other diseases that can present as cistic lesions, as neoplasms and other parasitic infestations, should be done $e^{31,44,45,72,83,87,91}$.

Intracranial giant cysticerci, whether of parenchymatous, ventricular or cisternal location, are most often of the racemose form $(66.7 \%$ of our cases and $81.8 \%$ of the cases reported by Facure et al. ${ }^{44}$ ) and do not appear to be affected by anticysticercal drugs such as praziquantel and albendazole. On the other hand, the risk of decompensation of intracranial hypertension in patients with Cysticercus cellulosae due to the inflammatory reaction triggered by cyst degeneration also contributes to the non-indication of specific drug treatment in these cases. patients submitted to surgical treatment to control increase ICP, $2.95 \%$ belonged to group I, $5.8 \%$ to group II and $91.3 \%$ to group III.

Because of their special characteristics of morbidity and mortality, the forms of neurocysticercosis in which intracranial hypertension develops usually require surgical treatment.

\section{A. Tumoral Form}

The tumoral form of neurocysticercosis corresponds to 22 to $67 \%$ of the hypertensive forms ${ }^{24,75,109}$. CSF examination usually does not contribute to the diagnosis of this form because the complement fixation reaction for cysticercosis are negative in most cases ${ }^{14,44,45,91}$. In addition, the risk inherent in spinal taps in patients with an expansive intracranial process often contraindicates perfoming this examination.

Carotid angiography only shows alterations suggesting an avascular expansive process $^{44,45,70}$ at time surrounded by contrast enhancement and with early venous drainage ${ }^{87}$, providing no detail that will allow identification of the cysticercus. On the CT scans of the skull, giant cysticerci usually appear as lesions with a

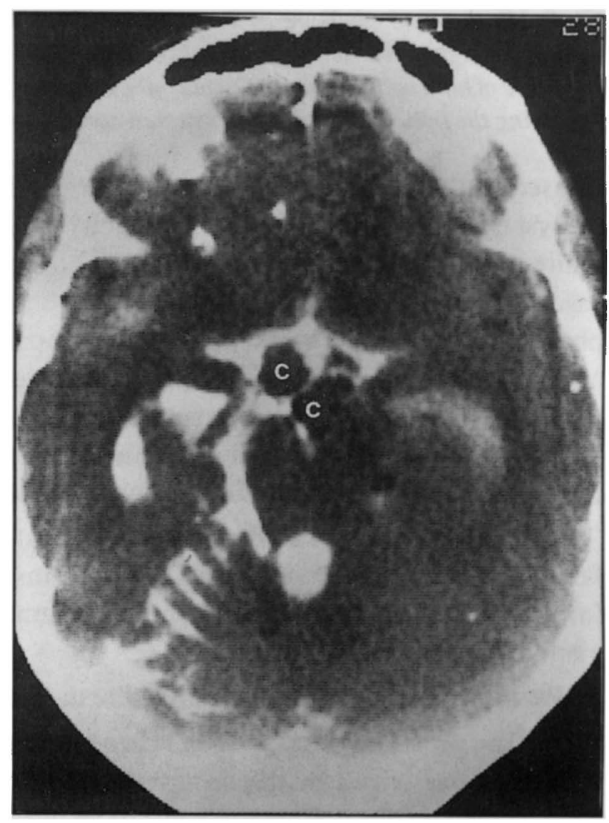

Fig 8. Cisternotomography of the skull showing two negative irregular images (c) in the optochiasmatic cistern suggestive of degenerating cysticercus (surgically confirmed). 


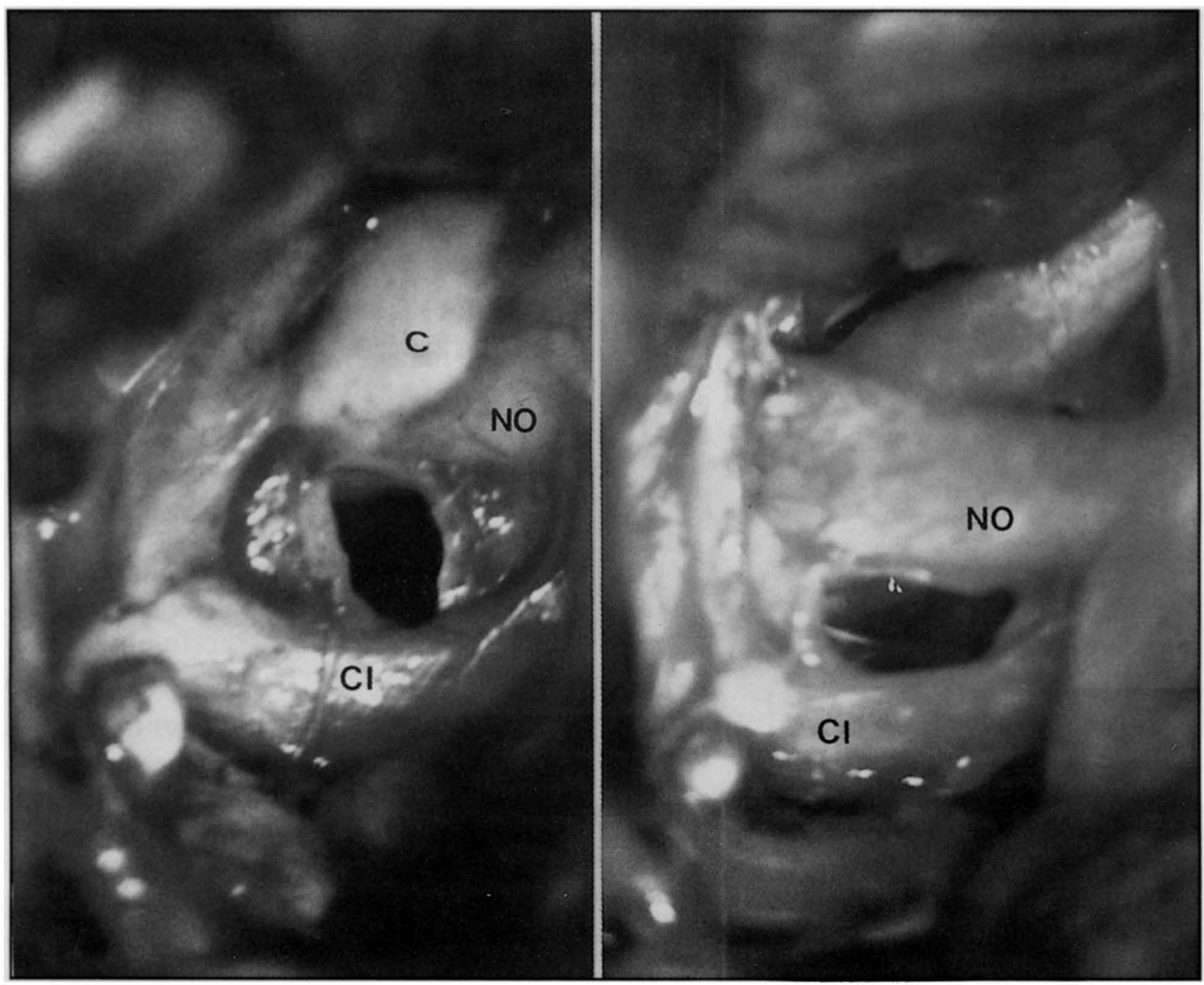

Fig 9. Microscopic exposure of the optochiasmatic region in a patient of figure 8. A. A degenerating cyst (c) adhered to right optic nerve $(N O)$ that is partially exposed. The intern carotid artery $(C I)$ is placed laterally. $B$. Exposure of both optic nerves (NO) and optic chiasm ( $Q$ ) after the removal of the cyst and lysis of the arachnoiditis envolving the optic nerves and the internal carotid artery $(\mathrm{CI})$.

Consequently, treatment of the tumoral form of neurocysticercosis is basically surgical and is based on cyst exeresis through a direct approach or at least on cyst emptying and partial resection through a direct or stereotaxic approach. Surgical exeresis is usually performed completely with relative ease when the giant cyst is located inside the parenchyma or in the cisterns and is still in its active phase (Fig 12), when it weakly adheres to the parenchyma, both in the case of Cysticercus cellulosae and Cysticercus racemosus. When the cysts enter their degenerative phase the inflammatory reaction around them becomes more intense and may make them adhere firmly to nervous tissue and to blood vessels, specialy those located in the cisterns, and the attempt to resect them, mainly close to the eloquent areas of the brain, is usually accompanied by a great risk of additional lesions.

In view of the possibility of decompensation of intracranial hypertension and of transtentorial herniation caused by the increase in the inflammatory reaction provoked by cyst degeneration ${ }^{97}$, we formally contraindicate specific clinical treatment with parasiticidal drugs in patients presenting giant cysticerci with a mass effect.

\section{B. Pseudotumoral or Encephalitic Form}

The pseudotumoral form of neurocysticercosis occurs in 9.4 to $43.5 \%$ of cases $^{9,24,73,92,113}$. This form is characterized by the occurrence of clinical manifestations of intracranial hypertension in patients who do not present evidence of an intracranial expansive process or of hydrocephalus. It is caused by a diffuse inflammatory reaction of the brain parenchyma generally due to massive infestation with cysticerci ${ }^{9,26,106}$ that may or may not be visualized by CT scans, which often only shows the increase in parenchymal volume with reduction of ventricular and cisternal volumes and 


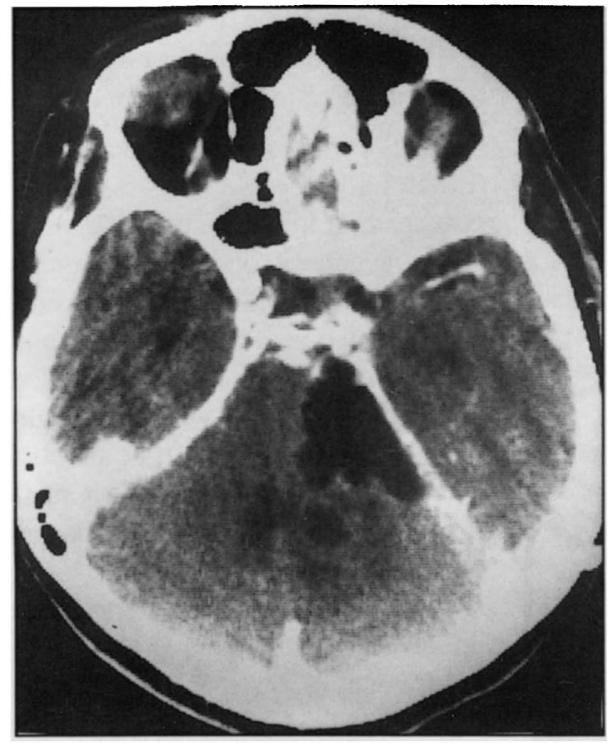

Fig 10. Computed tomography of the skull showing a multiloculate and hypondense lesion in the right cerebellopontine angle displacing the brain stem, suggestive of a racemose cysticercus. Duiring surgical exploration a racemose cysticercus with vesicles in different stage of evolution and associated arachnoiditis involving the cranial nerves and vessels were founded.

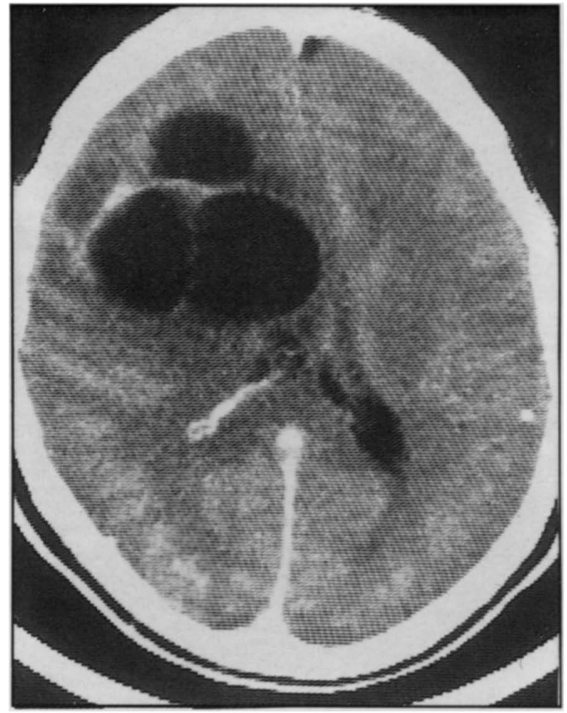

Fig 11. Computed tomography of the skull showing a parenchimatous frontopariental multiloculate and hipodense lesion, suggestive of a gaint racemose cysticercus.

cerebral edema (Fig 13), or circulatory disorders due to the inflammatory process revealed by irregular contrast retention in the parenchyma. This diffuse inflammatory

reaction, at times called cysticercotic encephalitis ${ }^{18}$, with an increased volume of the brain parenchyma, is more frequent in children ${ }^{18,20,42,51,95,106}$.

Treatment of the pseudotumoral form is clinical and is aimed at reducing the cerebral edema by using osmotherapy, corticosteroids and CSF puncture, with a good patient course in most cases ${ }^{9,18}$. Decompressive craniectomy used to be recommended in the past ${ }^{9,113}$ for these patients in order to avoid loss of vision by maintaining the papilledema, but the results obtained were only temporarily satisfactory ${ }^{106}$. In our opinion and in the opinion of other investigators ${ }^{18}$, the indication of decompressive craniotomy today is exceptional and should only be made in situations of extreme gravity as a heroic measure in an attempt to control intracranial hypertension. The use of lumboperitoneal shunts, as in pseudotumoral pictures of different etiology, does not seem to be a good solution for the treatment of these patients since, due to the pathophysiology of the process itself, intracranial hypertension is caused more by an increased volume of the brain parenchyma than by an increase in CSF volume.

\section{Forms in which Hydrocephalus Develops}

Hydrocephalus is the most frequent mechanism of intracranial hypertension in neurocysticercosis. Increased ICP may be caused by mechanical obstruction of the ventricles or basal cisterns by the cysts themselves or by an inflammatory reaction (ependymitis and/or arachnoiditis), or may be caused by difficulties in absorbing CSF due to parasagittal arachnoiditis, with involvement of arachnoid villi ${ }^{63,65,89,93,106}$. Obstruction by cysts usually occurs at points of constriction of the ventricular system, specially in the Magendie foramen and in the cerebral aqueduct, causing obstructive hydrocephalus, and when it occurs in the basal cisterns it determines communicating hydrocephalus. Obstruction by an inflammatory reaction is more frequent in the outgoing foramina of the fourth ventricle, in the posterior fossa and in the basal cisterns, but may occur at any point in 


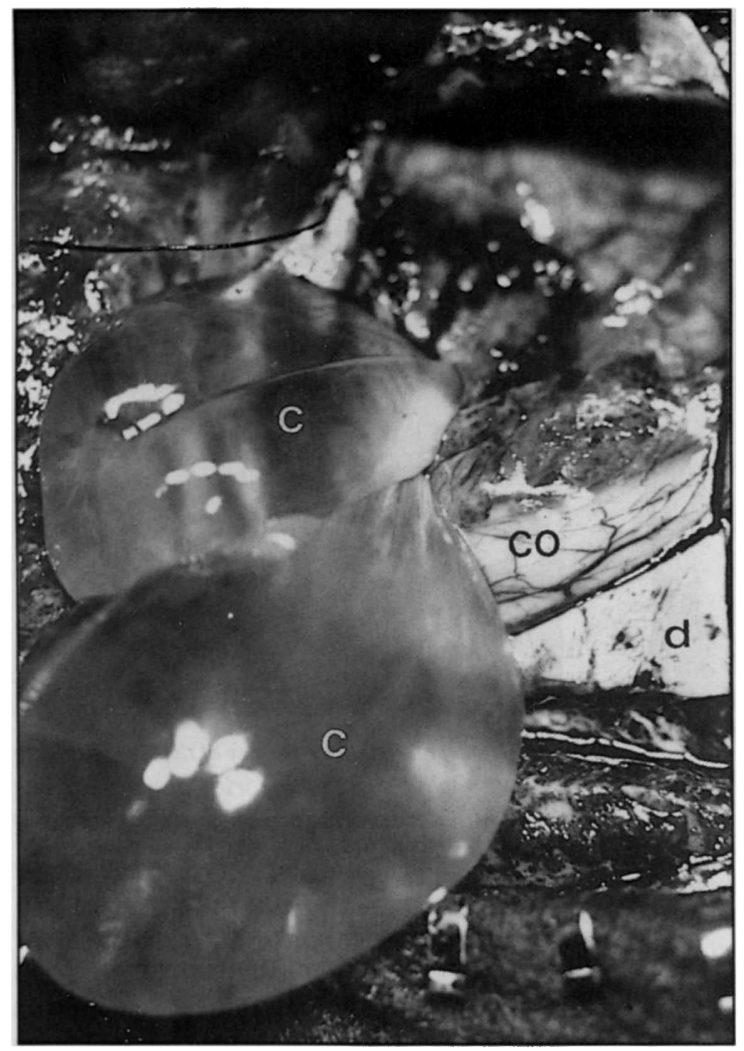

Fig 12. Surgical exposure of the patient of figure 11. After the duramater (d) was opened, due to intracranial hypertension, there was protrusion of two vesicles $(C)$ of an active parenquimatous racemose cysticercus that was superficial in the cerebral cortex $(\mathrm{CO})$. the CSF circulation, including sites of CSF absorption, and cause obstructive or communicating hydrocephalus.

For a rational treatment of hydrocephalus secondary to neurocysticercosis it is essential to identify the pathogenesis of the condition in each case. Ventriculography is a simple examination of easy execution and great accuracy for this purpose. Based on ventriculography, we have sought to identify the site and type of obstruction ${ }^{30}$, i.e., patients with obstruction by free cysts (Fig 14) who can benefit from cyst removal ${ }^{5,29,33,43,62,66,68}$, $93,107,118$, or patients with obstruction due to an inflammatory process (Fig 15) for whom a VPS is considered the best treatment ${ }^{3,28,33,52,62,66,118}$. This differentiation is impossible to do by CT scan because this examination not always permits an accurate identification of the site of obstruction and does not reveal free intra-ventricular cysts $^{31}$ because these cysts usually are in the active form and present density similar to that of CSF. The presence of an intraventricular cyst can only be suspected by CT scan based on morphological changes of the ventricles, specially rounding of the fourth (Fig 16A) or third ventricles or of portions of the lateral ventricles. CT-scan with intrathecal contrast permits the detection of cysts in the cisterns (Fig 17) and when there is no obstruction of the ventricular system or this obstruction is partial, it permits the identification of intraventricular cysts (Fig 16B). Combined ventriculography and CT scan permit and adequate evaluation of the ventricular system, even permitting the identification of cysts (Fig 18) not visualized by ventriculography ${ }^{30,67}$.

The implantation of a ventricular reservoir has been used routinely in our service as a measure for ventriculotomography and for the execution of punctures for the relief of intracranial hypertension, specially in patients with hydrocephalus caused by inflammatory diseases, until definitive therapeutic procedures are instituted. With this measure, patients with ventricular cysticerci can have their cysts removed without the implantation of a definitive CSF shunt.

The removal of free ventricular cysts is relatively simple when effected by an adequate approach and using a microsurgical technique, with minimal morbidity and mortality. This procedure is justified because free cysts may dislocate within the ventricular system (Fig 19) and cause acute intracranial hypertension by obstruction of CSF circulation and because intraventricular cysts tend to increase in size and start to behave as an intraventricular tumor, specially in the fourth ventricle.

Access to the fourth ventricle is obtained by craniotomy of the posterior fossa and the free cyst protrudes spontaneously through the Magendie foramen toward the cisterna magna ("delivery" of the cysticercus) or it may be gentily pulled out of the ventricle. When the cysticercus adheres to 


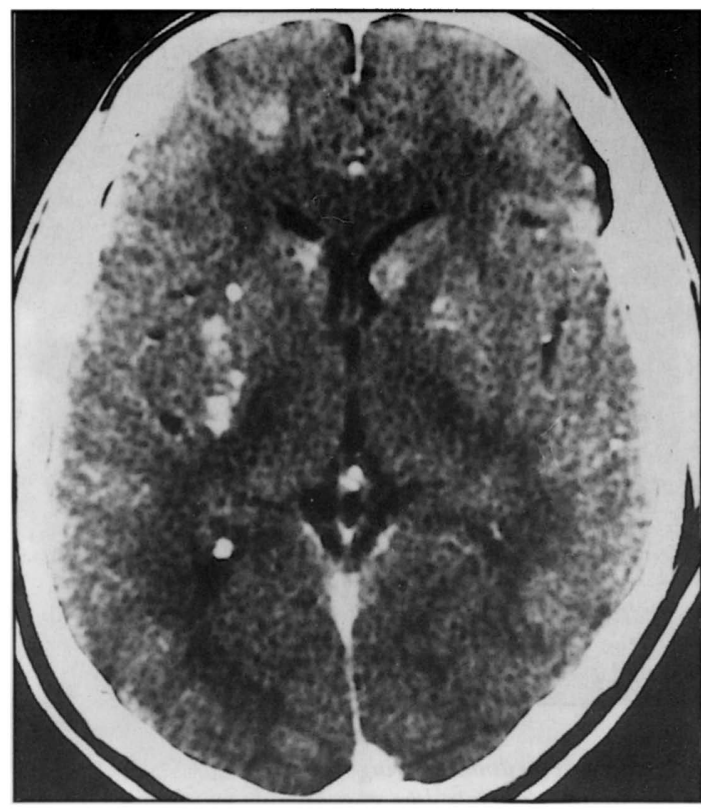

Fig 13. Computed tomography of the skull of a patient with intracranial hypertension, showing calcifications mainly in the basal ganglia and reduced ventricles due to difuse enlargement of the cerebral parenchyma, characterizing the picture of pseudotumor cerebri. the wall of the ventricle or the Magendie foramen is stenosed or obstructed, the foramen needs to be opened or widened with section of the inferior portion of the cerebellar vermis to facilitate the visualization of the inner part of the ventricle.

Free cysts located in the lateral ventricle and in the third ventricle need to be operated upon using an anterior transcallosal approach. We indicate a direct approach and cyst exeresis in the lateral ventricles when the cysts are free, because of the risk of dislocation. When the cysts adhere to the walls of the lateral ventricles, we indicate exeresis only when they cause septations of the cavities and/or obstruction of CSF circulation. In these cases and when the cysts are located in the temporal horn, transcortical pathways may be more adequate.

The mortality of patients submitted to CPF ranges from 0 to $60 \% \%^{7,29,33-}$ 35,64,65-66,68,71,106,118. The lowest mortality rates are observed when the treated patients present free ventricular cysts,

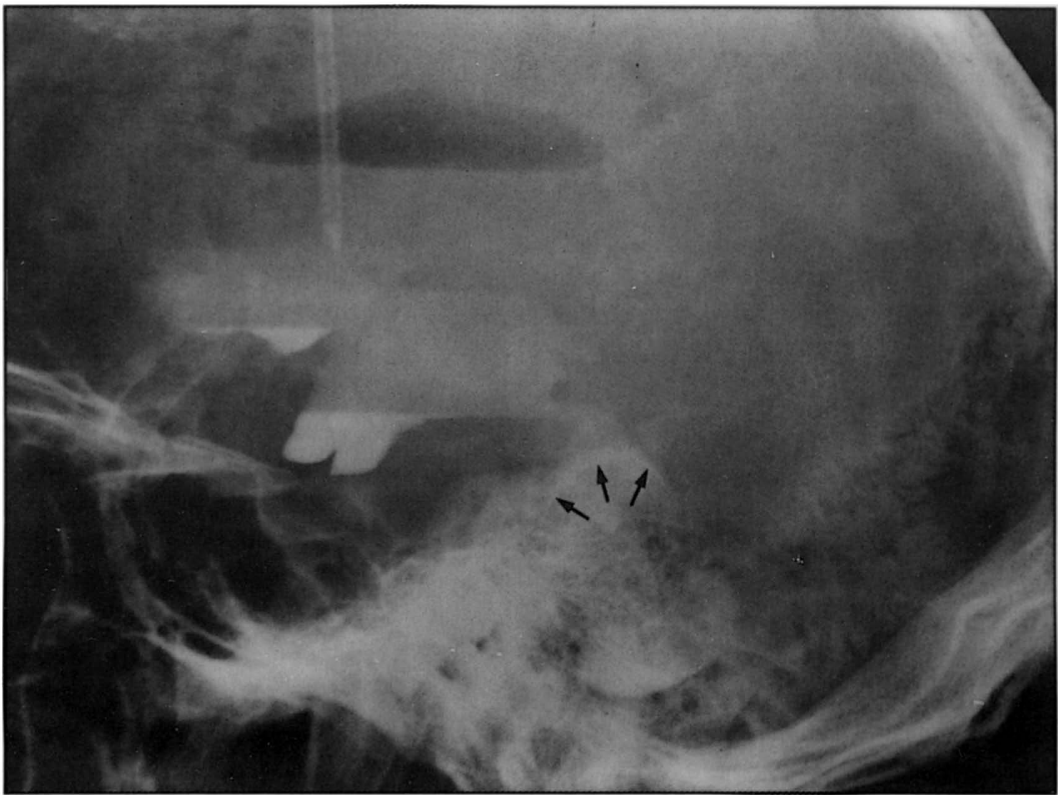

Fig 14. Ventriculogram with positive contrast medium showing hydrocephalus and a negative rounded and well delineated image in the fourth ventricle suggestive of free cyst. During surgery it was found an active cyst in the fourth ventricle. 


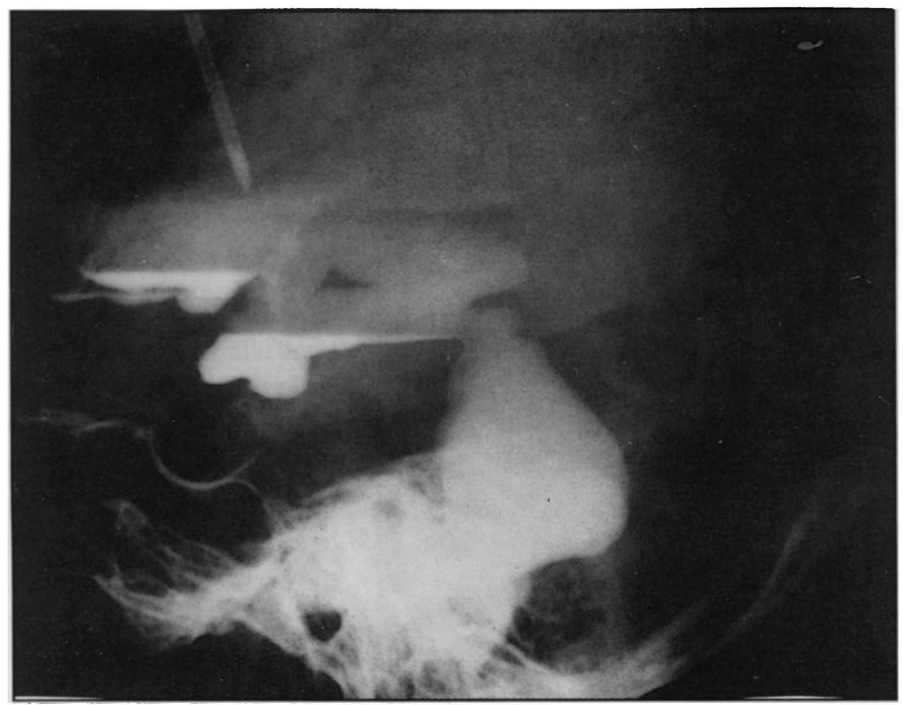

Fig 15. Ventriculogram with positive contrast medium showing hydrocephalus and inflammatory obstruction of the fourth ventricle (the contrast medium delineates a cul de sac).

and the highest rates occur when the patients present obstruction due to an inflammatory reaction or cysts associated with the inflammatory reaction. For this reason, we try to identify patients presenting free ventricular cysts and we indicate a resection by a direct approach only in these cases. The high mortality and morbidity rates observed in the past among patients submitted to

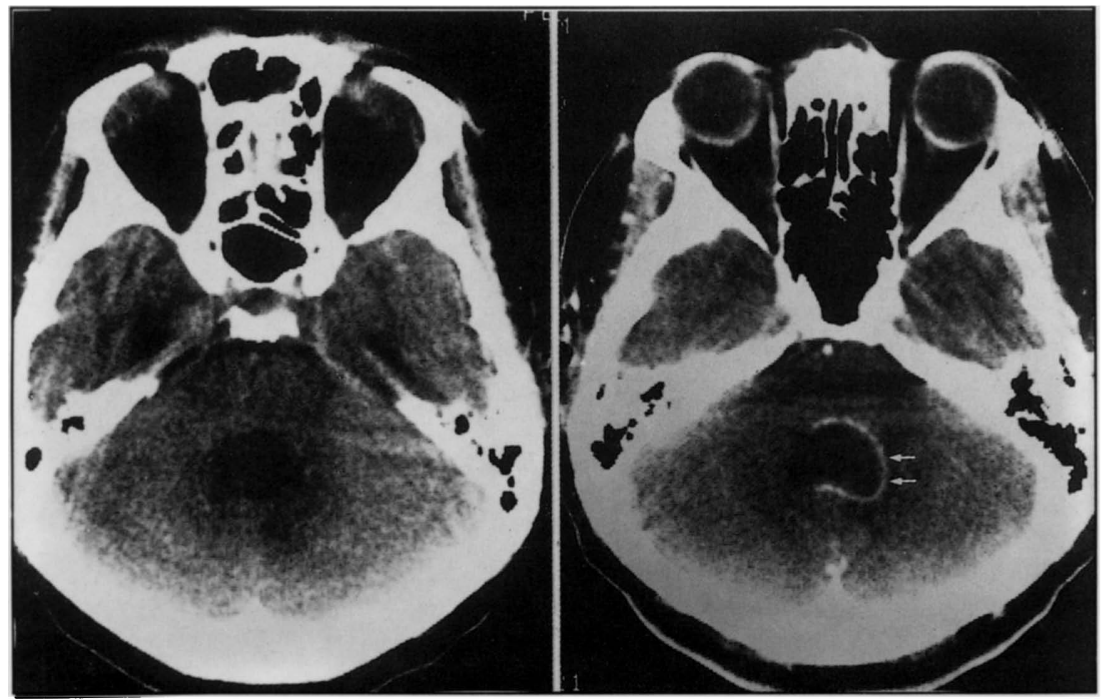

Fig 16. Computed tomography of the skull. A. Examination showing the fourth ventricle rounded and enlarged, that suggests the presence of a cysticercus. B. Cisternotomography showing the contrast medium (arrows) delineating a cysticercus placed in the ventricle. During the surgery it was found a free active cyst in the fourth ventricle. 


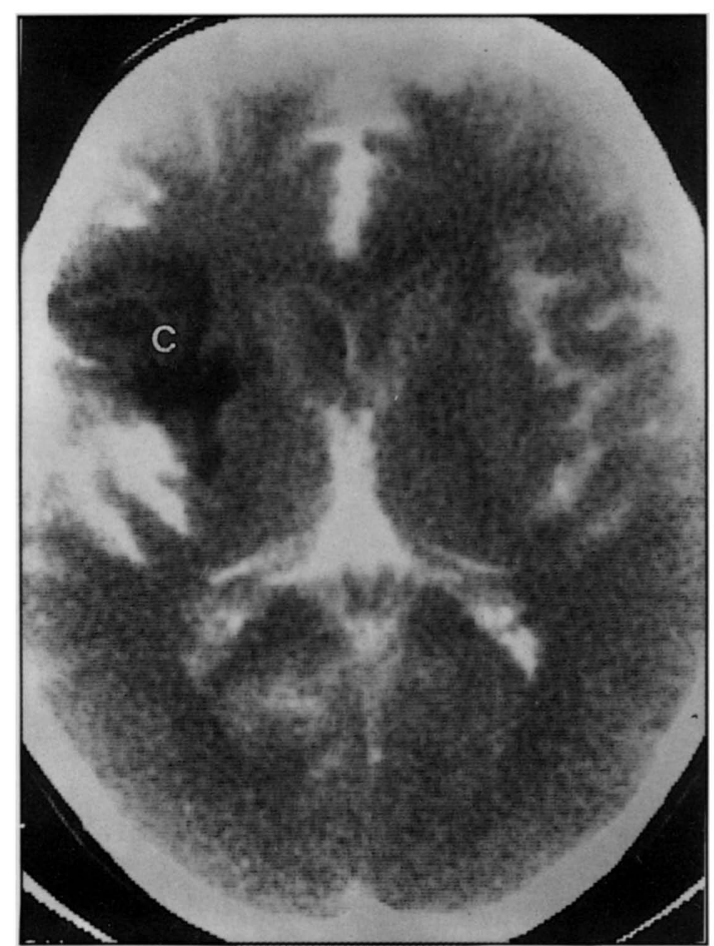

Fig 17. Cisternotomography of the skull showing a negative and irregular image $(C)$ in the left silvian fissure, suggesting $a$ racemose cysticercus. During the surgery a racemose cysticercus with active and degenerating vesicles placed along the silvian fissure and associated arachnoiditis were found.
CPF were related to the difficulties in the surgical management of patients with arachnoiditis and aseptic meningitis caused by cyst rupture during surgery. Today these problems have been reduced to a minimum by a better identification of patients with free cysts, by using microsurgery techniques and by the satisfactory control of aseptic meningitis with corticosteroids. With the routine use of corticosteroids during surgery and during the postoperative period we did not observe clinical manifestations of an inflammatory reaction due to cyst rupture, although this reaction may be detected by CSF examination.

Most of our patients with inflammatory obstruction of CSF circulation were directly submitted to a VPS because our previous experience $e^{33,34}$ and the experience of others ${ }^{45,55,57,89,118}$ has shown that these patients do not benefit from a direct approach to the posterior fossa for lysis of the inflammatory reaction, which recurs within a short time (generally a few weeks), and that serious complications due to this procedure may occur ${ }^{33,34}$. The VPS has been considered the best treatment for patients with hydrocephalus due to inflammatory obstruction caused by cysticercosis, permitting the relief of intracranial hypertension in 50 to $90 \%$ of cases. In our experience, most patients with more than 2 years of evolution were free from hypertension at the end of this period and more than half of them required revisions of the shunt, most of them during the first postoperative year, as previously observed by $u^{28,33,34}$ and by others ${ }^{71}$. The predominance of complications during this period is probably because in patients with multiple cysts most of the cysts degenerate during this period. Another possibility is that during this time these patients reach functional equilibrium in CSF circulation and no longer require the shunt, which may not be functioning.

Isolation of the fourth ventricle has been related in several diseases of the CNS, including cerebral cysticercosis ${ }^{35,37.39}$, mainly in that patients submitted to a VPS. We observed this complication in 4 patients and the particularities of this entity were discussed in previous study ${ }^{36}$.

In the opinion of some investigators ${ }^{43,65,67}$, the VPS should be performed as the first surgical procedure for all patients with hydrocephalus secondary to cerebral cysticercosis in order to relieve intracranial hypertension, and the ventricular cysts should be removed during a second stage. Today we prefer to first control intracranial hypertension with the implantation of a ventricular reservoir and decide in advance whether the patient will benefit from the removal of a free cyst or whether a VPS will be the best treatment. This strategy has been adopted because of the risks posed by technical difficulties in approaching the fourth ventricle in the presence of an inflammatory reaction and of collapse after a VPS, and to insure that some patients will not receive an unnecessary shunt. 


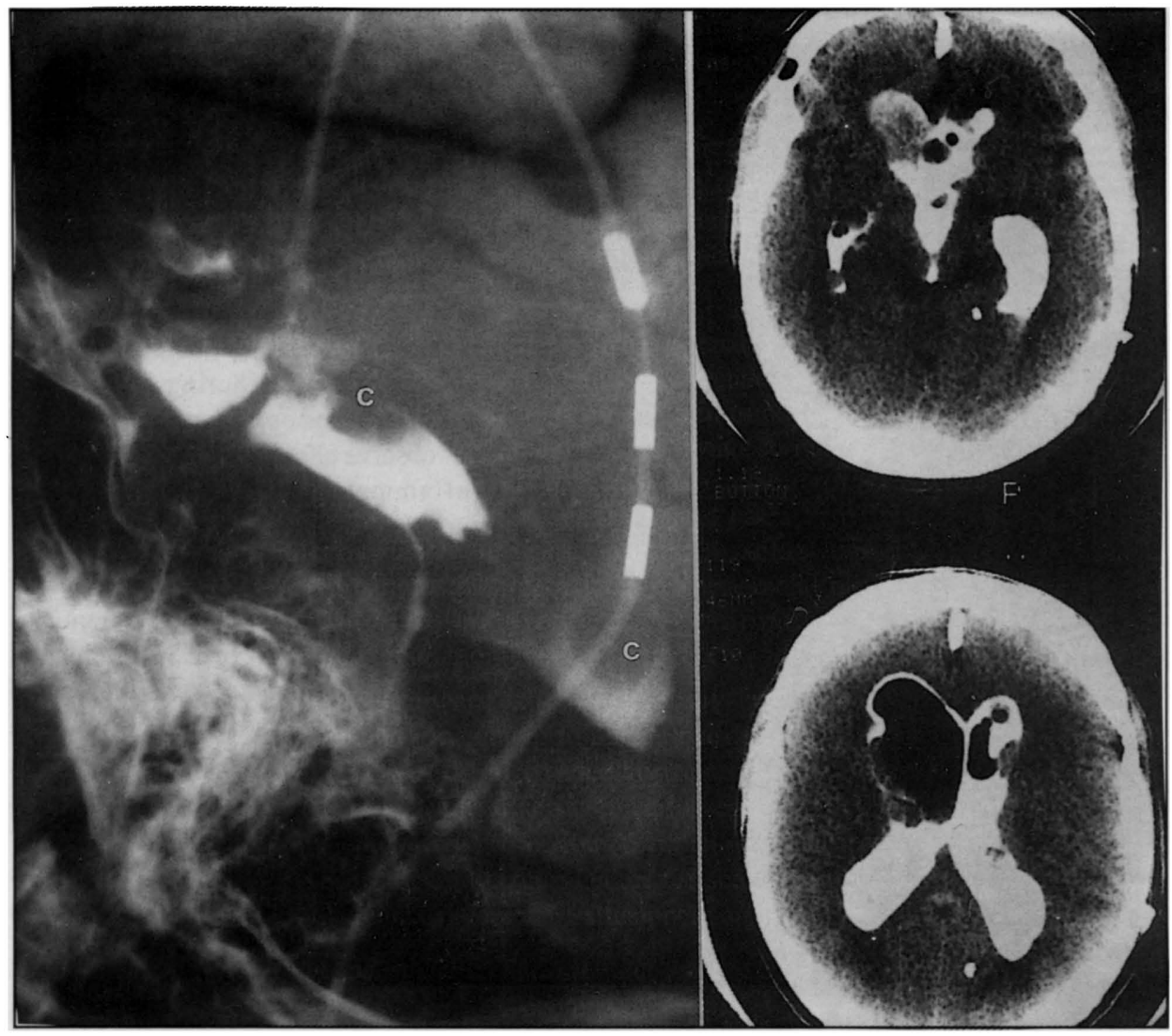

Fig 18. A. Ventriculogram with positive contrast medium showing rounded negative images (c), suggestive of cysticercus, in the third and lateral ventricles but it was not possible to place the contrast medium in the anterior part of the lateral ventricles. B. Ventriculotomography of the skull of the same patient showing negative images suggestive of cysticercus in the lateral ventricles, that impeded the complete visualization of the ventricles in the ventriculogram.

When ventriculography and/or CT or a combination of the two examinations, or MRI do not allow differentiation between an inflammatory obstruction and an obstruction due to free cysts, a direct surgical approach should be indicated with great care taking into consideration the advantages and disadvantages of a ventricular approach.

Other procedures such as a cystoperitoneal shunting ${ }^{8}$, stereotaxic approaches with cyst resection or drainage with or without reservoir implantation ${ }^{6,23,27,38,112}$ and cyst drainage or resection by the endoscopic route ${ }^{59}$ have been proposed as alternatives to exeresis of giant parenchymatous cysts and ventricular cysts. Cyst emptying through puncturing may be an effective procedure since theoretically cyst rupture triggers the process of cyst degeneration. Cyst recurrence after puncture and drainage $e^{23,38,107}$ should be attributed to the existence of several vesicles of a racemose cyst at the punctured site. By being less invasives, these methods may become the procedure of choice for this treatment, specially the endoscopic route which permits manipulation under direct vision and identification of multiple vesicles.

In patients with giant parenchymatous cysts we prefer the direct surgical approach since this is relatively safe when the surgical strategy used is appropriate, it permits a thorough evaluation of the adherence of cysts in relation to adjacent structures and the resection or emptying of the various vesicles of a racemose cysticercus, and has given good results in our cases. We also opt for a direct approach to free ventricular cysts because during the surgical act we can identify the presence of 


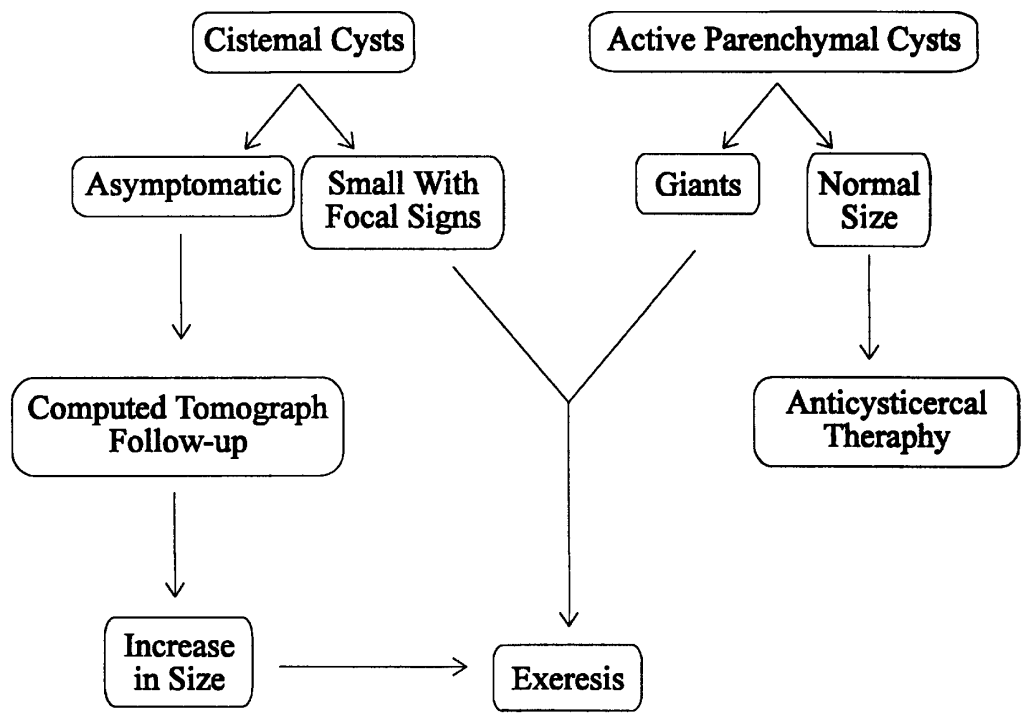

Diagram 1. Flow diagram for the management of patients with cisternal cysts and active parenchymal cyst.

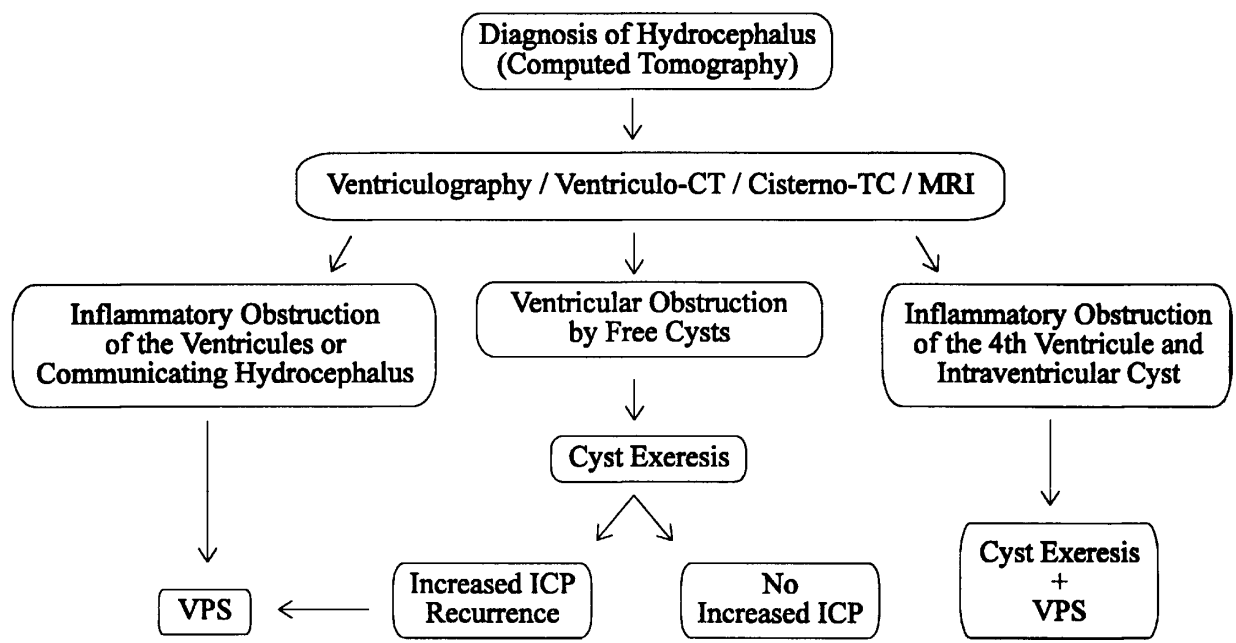

Diagram 2. Flow diagram for the management of patients with hydrocephalus due to cerebrat cysticercosis. CT, computed tomography; ICP, intracranial pressure; MRI, magnetic resonance image; VPS, ventriculoperitoneal shunting. 


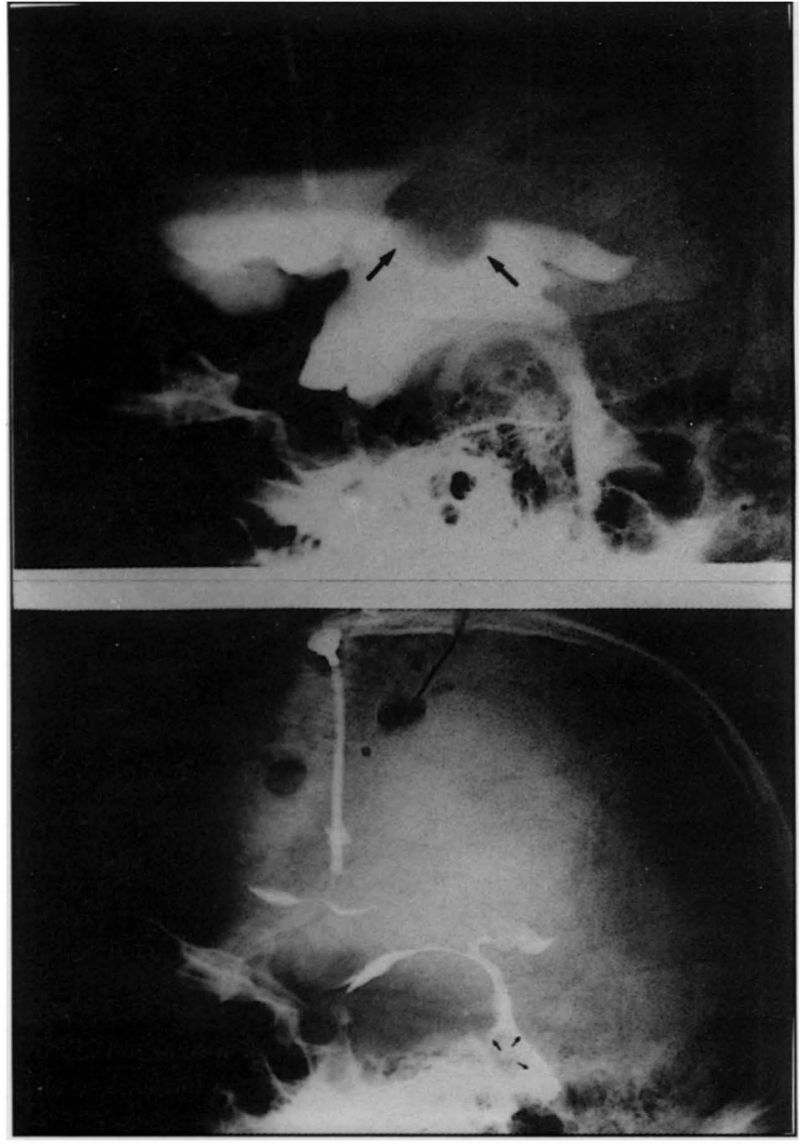

Fig 19. Ventriculograms with positive contrast medium. A. Rounded and mobile negative image in the third ventricle (arrows) suggestive of a free cyst that was not found during a transcallosal approach. $B$. Examination repeated after the surgery showing that the cyst has migrated to the fourth ventricle (arrows). associated ependymitis or arachnoiditis and when these reactions are intense we indicate the VPS immediately after cyst removal, since in our experience these patients usually develop inflammatory blockade of the CSF circulation and intracranial hypertension within a few weeks.

In our opinion, there is no advantage in resecting the granuloma that forms around the cyst as proposed by Caldwell et al. ${ }^{38}$ and we do not recommend procedures carried out to drain the cyst into the subarachnoid space since the fluid in the cyst triggers an intense immuno-allergic reaction despite the use of corticosteroids, as frequently observed when the CSF is examined immediately after surgery.

Conclusion. On the basis of the experience acquired in the management of patients with cerebral cysticercosis, we indicate clinical/surgical treatment in the following situations:

1. Patients with the pseudotumoral form of the disease are treated with clinical measures for the control of intracranial hypertension. Exceptionally they are submitted to decompressive surgery as an extreme measure to try to control hypertension resistant to clinical treatment.

2. Patients with active cysts of normal size in the brain parenchyma are submitted to specific treatment with anticysticercal drugs. Giant cysts which exert a mass effect are removed by a direct approach.

3. Patients with cysts located in the cisterns are submitted to surgical cyst removal only when the cysts cause local compression symptoms (specially of the cranial nerves), regardless of size.

4. Patients with free cysts in the third or fourth ventricles are submitted to a direct approach for cyst exeresis. Cysts located in the lateral ventricles are removed only when they are free or when, despite the fact that they adhere to the ventricular walls, they exert a mass effect because of their size or due to ventricle obstruction/septation. When there is an association of an important inflammatory reaction (arachnoiditis and/or ependymitis), the patients are simultaneously submitted to VPS.

5. Patients with communicating hydrocephalus or hydrocephalus caused by inflammatory obstruction are directly submitted to VPS.

6. Whenever there is evidence of an inflammatory reaction in the spinal canal or in the brain observed during the surgical act or by CSF signaling, or when there is intraoperative cyst disruption, corticotherapy is instituted in association.

Diagrams 1 and 2 present the flow diagrams for the care of patients with cystercosis of the CNS.

\section{REFERENCES}

